Vegueta. Anuario de la Facultad de Geografía e Historia

22 (1), 2022, 289-323

eISSN: 2341-1112

https://doi.org/10.51349/veg.2022.1.15

\title{
Los remates de cubierta o de composición en los edificios canarios 1896-1931: tratamiento y utilización por los técnicos
}

\author{
The Capstones of Roof Ornaments of Canary Buildings 1896-1930: \\ Treatment and Implementation by Architects
}

\author{
José Antonio Sabina González \\ Universidad de La Laguna \\ Escuela Politécnica Superior de Ingeniería \\ Departamento de Técnicas y Proyectos en Ingeniería y Arquitectura \\ https:/ / orcid.org/0000-0001-7044-465X \\ jsabinag@ull.edu.es
}

Recibido: 25/01/2021; Revisado: 13/06/2021; Aceptado: 26/10/2021

\begin{abstract}
Resumen
Gran parte de nuestro patrimonio arquitectónico cuenta con ciertos elementos decorativos característicos del estilo ecléctico y modernista que caracterizaron a una época pasada de gran esplendor. Uno de ellos es el remate que estudiamos en el presente artículo, un ornato que culmina un edificio perfectamente ornamentado y del que los técnicos disponen en algunos de sus inmuebles; un elemento que se expondrá con ejemplos de su procedencia externa. Este trabajo contará con estos técnicos para profundizar en este elemento decorativo, mediante la consulta de los planos de sus edificios que cuentan con este ornato en Tenerife, entre los años 1896 y 1931, examinando la documentación de los archivos municipales para poder complementar la información existente sobre estos profesionales, y de esta manera llegar a obtener revelaciones sobre el estilo, las particularidades y las preferencias de ellos, con respecto a este componente decorativo.
\end{abstract}

Palabras clave: Detalle, decoración, fachada, arquitectura. 


\begin{abstract}
Much Canarian architectural heritage reflects certain decorative elements characteristic of the eclectic and modernist style that signals a bygone era of great splendour. One of them is the capstone covered in this article, the culmination of a perfectly ornamented building as employed by some architects, an element that will be detailed here with examples. This article explores this decorative element by consulting architects' plans for buildings that made use of the ornament in Tenerife between 1896 and 1931, examining the documentation of the municipal archives as a complement to extant information on these professionals. By doing so, the article analyses such architects' styles, particularities and preferences with respect to this decorative component.
\end{abstract}

Keywords: Detail, Decor, Façade, Architecture.

\title{
1. INTRODUCCIÓN
}

El embellecimiento de todas nuestras obras siempre ha sido un patrón que nos ha ido acompañando desde las más antiguas épocas. Cualquier monumento gana en majestuosidad si se tiene en cuenta la decoración en él, que puede ser con cierta opulencia en su justa medida, o con simplicidad de formas.

Las distintas variantes se materializan en multitud de conceptos, que pueden generar confusión de términos: En el campo de la arquitectura, el término decoración puede aplicarse a las partes activas o estructurales y el concepto de ornamentación a las pasivas o no estructurales (Espasa, 1991: 560-561), aunque parezca que lo estructural no tiene nada que ver con lo estético.

Continuamente aparecen nuevas tendencias, pero la moda del momento puede consistir en volver a los antiguos estilos: en el Renacimiento el arte clásico de Grecia y Roma reaparece en diversos soportes, con motivos ornamentales sobre el hombre o la naturaleza plasmados en frisos, capiteles etc. (Arabescos, 1996: 7). En un momento dado la decoración puede ser minuciosa, como ocurrió con el plateresco, y pasar a reducirse drásticamente como sucedió con la arquitectura herreriana, con su periodo de transición.

Con respecto a los lenguajes más importantes de la cronología propuesta, podemos recordar muy brevemente algunas de sus características, ya sabidas: en el caso del Eclecticismo, el más prolífico, su característica principal es la reunión de elementos de otros estilos, tanto del pasado como del momento pero con cierta armonía; Manuel Goicoechea indica que el resultado final debe mantener un carácter unitario (GAGO, ed., 1989: 32). Estos motivos que pueden ser tanto orgánicos como geométricos y ya no es necesario respetar las exigencias formales de lenguajes pasados, con lo cual la inventiva del arquitecto juega un papel fundamental, pero no todos están de acuerdo con la legitimidad de este estilo: Franchez afirma que si se copia de otros lenguajes no estamos ante un lenguaje genuino (FrancheZ, 2009: 315). Pero otros autores opinan que si los detalles que se toman son los de más clase, al consolidarse, estamos ante un lenguaje único y perfectamente válido (GARCíA, 1996: 315). Fernández lo sintetiza perfectamente al afirmar que estamos ante un estilo con una capacidad creadora innovadora, que desarticula lo instaurado en la Academia o en la tradición, liberando al arquitecto de impedimentos formales de otros lenguajes para permitirle desarrollar su capacidad creadora (FERNÁNDEZ, 1995: 15). 
En el caso del Modernismo se encuentran menos ejemplos en Tenerife porque su etapa solo duró 10 años como indica Darias, con arquitectos que promovieron este estilo como Antonio Pintor y Mariano Estanga (DARIAS, 2004: 70-81). Lo que sí es muy usual es incorporar detalles puntuales modernistas en gran número de edificios, como algunos herrajes de antepecho o tragaluz. DARIAS nos comenta que este lenguaje perteneció más bien a la clase alta, pues adoleció, cuando lo encontramos en ejemplos de otras clases (DARIAS, 1985: 87). En el caso de Gran Canaria, fue el arquitecto catalán Laureano Arroyo el que utilizó este lenguaje en Las Palmas, también con detractores por la introducción de algo de lo que no se está acostumbrado (DARIAS, 1985: 78-79); además de Fernando Navarro también en Las Palmas (GAGO, ed. 1989: 39).

El modernismo intensifica aún más la naturaleza, con ondulaciones pronunciadas a las que los tallos y hojas se prestan perfectamente a modo de golpe de látigo, con una libertad creadora aún mayor que con el Eclecticismo, con lo que la controversia también ocurrió con este lenguaje. OTERo afirma la necesidad de modificar la rigidez arquitectónica de la tradición para dejar libre la inventiva, aunque para muchos el modernismo era algo ridículo, que además se agravaba porque también copiaba elementos de otros estilos, como también ocurría con el Eclecticismo (Otero, 1991: 430, 437, 435, 442). María Pilar Poblador comenta que debe innovarse, los lenguajes pasados deben dar paso a las nuevas ideas modernas (PoBlador, 2004: 15).

A Canarias llegan estas expresiones artísticas por diversas fuentes: se establecen en las islas personal extranjero por motivos comerciales, hecho que también trae consigo la importación de ideas novedosas, innovaciones constructivas, nuevos materiales o el aprovechamiento de los que aquí se encuentran, como indica MARTín (1978: 37-38).

Por otro lado, también en esta tierra se animaba a estar al tanto de las nuevas tendencias ornamentales del momento, como las eclécticas, tarea protagonizada por los profesores de la Escuela de Arquitectura creada en 1844, cuya generación provocó la existencia en las islas de edificios de gran importancia ornamental, aunque como indica el profesor DARIAS, la decoración de las fachadas canarias no puede calificarse como algo habitual (DARIAS, 1991: 66).

Pero no solo estas fachadas reflejan el sentir de los técnicos, sino de la ciudad, que vivía un momento en el que el desarrollo de los transportes, la exportación de productos agrícolas, o la aparición de los Puertos Francos provocó el afincamiento de empresas extranjeras navieras dedicadas al comercio (DARIAS, 1985:17-18). La nueva clase social comerciante, establecida como consecuencia de este movimiento portuario, solicitaba distinguirse para mostrar su nivel a los demás, y como indica García, recurriendo al Eclecticismo, el lenguaje de moda, con diseños majestuosos que lo manifiesten (GARcíA, 1996: 315-320). Esta circunstancia favoreció un movimiento cultural innovador que cambió las formas arquitectónicas antes establecidas (GAGO, ed., 1989: 11).

En general, la decoración de estos estilos se reparte por toda la fachada, pero si nos referimos concretamente a nuestro elemento, suele ubicarse en la parte superior de algunas disposiciones ornamentales. Estas pueden ser un frontón dispuesto sobre una puerta de entrada, una balaustrada de un balcón, un antepecho de cubierta, etc, pero como su naturaleza es culminar superiormente una composición de cierta altura, el lugar más habitual y frecuente es la cubierta.

En ella, se disponen varios elementos similares, como los espigones, que 
a pesar de disponer de nombre propio puede considerarse como un remate, pero más altos, que coronaban tejados y cresterías en la Edad Media o en el Renacimiento. Estaban formados entre tres y seis piezas de metal, barro vidriado o cocido, insertadas en una barra metálica que se fijaba inferiormente a la cumbrera por medio de clavijas. Su altura solía ser de uno a cinco metros de alto y podía decorarse con motivos vegetales, aves (PlAzA, 2012: 293).

También podemos considerar como remates a los pináculos, pero son también más altos que nuestro ornato, con formas más específicas piramidales o cónicas, propios de la arquitectura gótica. Realmente son evoluciones de las torres románicas cónicas, cuya forma en el siglo xIII llegó a convertirse en una pequeña torre de líneas en hélice decoradas con motivos vegetales y figuras sacras. Su evolución continúa, pues en el siglo XIV se decoran más aumentando su esbeltez, $\mathrm{y}$ en el Barroco se transforman en un piramidón de base adornada. El siglo xx continúa su presencia en diversos estilos, como puede ser con el Modernismo, decorados con uvas o espigas (PLAZA, 2012: 464).

Algunos edificios también se remataban por medio de una aguja, que es una torre esbelta y aguda propia del estilo gótico. Surgió en el siglo XI como una pirámide para rematar una torre campanario, pero también evolucionó, porque su planta se convirtió en octógono, llegando a situarse sobre las cumbreras de los cruceros en las iglesias. También llegaron a adoptar formas cónicas o hexagonales, elaborándose de hierro las más modernas (PLAZA, 2012: 30).

Los ejemplos expuestos suelen poseer una esbeltez y altura considerable con respecto al remate que estudiamos, pero también se encuentran otros de formas reconocidas, que también decoran a modo de remate, pero de menor altura que nuestro ornato, como son las acróteras. Este elemento remata los vértices de una cubierta, o las esquinas de un frontón, y como este último puede ubicarse sobre un hueco de puerta ya podemos encontrarlas fuera de la techumbre. Para los antiguos griegos inicialmente se trataba del pedestal que soportaba al ornamento, pero para los romanos ambos elementos se consideraban una acrótera, con formas de palmeta para el orden dórico, de influencia persa en el jónico y con forma de grifo en el corintio. En China formaban animales fantásticos en línea sobre el caballete o en la esquina del tejado para también asegurar las tejas al caballete, pero realmente las acróteras occidentales cumplían una función principalmente ornamental (PlAZA, 2012: 24-25).

Como se ha indicado, en muchos de estos ejemplos se han producido evoluciones. Si a ellos les combinamos la forma ancha y reconocida de un jarrón, resulta un cuerpo con tapa fija y ya nos acercamos al ornato que estudiamos en el presente trabajo. Y cuando se disponen en las fachadas, muchos autores los nombran como remates:

Antonio Sancho se refiere a estas formas como remates en la imagen 122 de una de sus obras (SANCHO, 1947); al igual que Gallardo, cuando estudia los edificios clasicistas románticos y sus pebeteros (GALLARDO, 1984: 32); y Darias, que cuando su forma se aleja de los pináculos y adopta este diseño voluminoso los llegó a nombrar como remates circulares (DARIAS, 1985: 148).

En esta línea se pretende investigar sobre la manera que han tenido los técnicos de Tenerife de representar este elemento decorativo, el estilo particular de cada uno o sus preferencias y al mismo tiempo mostrar algunos diseños de la cronología propuesta, porque pertenece a un rango en el que formaba parte un 
estilo ornamental tan expresivo como el Eclecticismo.

\section{METODOLOGÍA}

Para estudiar nuestro elemento decorativo desde el punto de vista de los técnicos es necesario acceder a sus diseños, y para ello la consulta de sus planos es fundamental. Por tanto, se visitan los archivos municipales y se comienza a consultar los planos de todos los expedientes por orden cronológico, de forma que cuando muestren nuestro remate se anotan los datos principales del mismo.

A continuación, se realizan fotografías de los planos con una cámara digital réflex Nikon D-90 y con un objetivo AF-S DX 18-55/3.5-5.6G VR. Se realizan fotos generales de la fachada y fotos específicas del remate. El material digital se organiza en carpetas cuya numeración coincide con el $n^{\circ} .^{\circ}$ del expediente. Seguidamente se confecciona una tabla con información de cada edificio, como al año, archivo municipal, etc. para tener una visión de conjunto.

Los edificios se incluyen en la tabla agrupándolos por técnicos, y se elige ordenarlos de forma que se parte de los que cuentan con menos cantidad de edificios con nuestro ornato y se dejan para el final a los que más. Dentro de cada uno de estos agrupamientos se realiza una ordenación cronológica, para poder identificar sus posibles evoluciones ornamentales y finalmente se les añade el número de orden definitivo. Para evitar que la tabla sea excesivamente grande se decide dividirla por técnicos.

Para el análisis se sigue este $n{ }^{\circ}$ de orden, abriendo cada archivo y consultando cada plano para su estudio. En los casos que resulte un número excesivo de edificios se opta para agruparlos por años para su análisis, centrándonos en la información más relevante para que no resulte excesiva, especialmente la de los técnicos más prolíficos.

Los archivos municipales han sido determinantes para fijar la cronología, porque incluyen la fecha del expediente, de forma que ha resultado entre 1896 y 1931, años que corresponden al edificio n. ${ }^{\circ} 1$ del arquitecto Manuel de Cámara de 1896 y los n. ${ }^{\circ} 19$ y 20 del arquitecto Felip Solá para 1931

Las fechas forman parte de un rango temporal en el que imperaba el ornato en la fachada, principal protagonista de los lenguajes que dominaban esa época, como el Modernismo y el Eclecticismo, en el que se ha fundado la tesis que ha servido de base para la elaboración de este artículo (SABINA, 2019: 42)

\section{EL ORNATO EN SÍ Y SUS VARIANTES}

El ornato estudiado es un elemento insertado, que suele colocarse en zonas altas o destacadas como los antepechos de los balcones para culminar la decoración de un edificio, por lo que generalmente se encuentra en la cubierta, su ubicación más habitual. No obstante, aunque se nombre como remate de cubierta, debe aclararse puede estar presente en menor grado en otras zonas generalmente de cierta altura de la fachada.

En la figura 1 se puede ver un ejemplo de una de sus formas, pues posee muchas variantes similares a una urna o pebetero, pero sin estar abierto por la 
parte superior. En la fachada de la figura 1 se puede entender la función que desempeñan estos elementos. Cuando se trata de una fachada de pocas plantas o una a lo sumo, si se dispone en la cubierta, su presencia concluye la decoración de la fachada con un elemento elegante, de forma que más allá del mismo no necesite nada más en altura. Posee una proporción media con respecto al conjunto, apropiada para que permita su identificación desde el vial, generalmente en la parte más alta, en el lugar más vistoso.
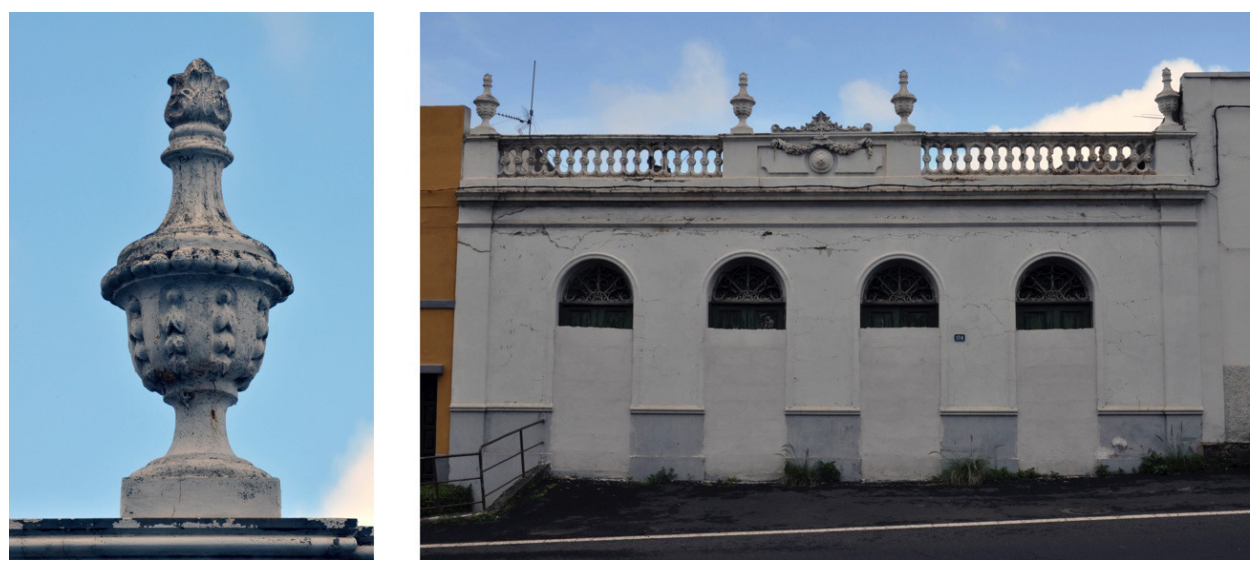

Figura 1. Remate de cubierta del edificio de la Carretera General TF-217 n. ${ }^{\circ} 174$. La Victoria. Tenerife (izquierda). Fachada del edificio de la Carretera General TF-217 n. ${ }^{\circ} 174$. La Victoria. Tenerife (derecha). Fotos: José Antonio Sabina González.

La variedad de este tipo de ornamento se encuentra desde el diseño más sencillo y geométrico, como puede ser una simple esfera, al ornato más elaborado con inclusiones de motivos vegetales. No obstante, pueden encontrarse otras formas diferentes que deben clasificarse aparte, como por ejemplo los jarrones, por estar abiertos superiormente; la coronación de cubierta, elemento generalmente geométrico más sencillo y más corto que disimula ser un elemento insertado, pareciendo más bien una prolongación de ella o del antepecho donde apoya; o elementos ya nombrados anteriormente como son: los pináculos, más puntiagudos y usualmente con perímetro piramidal o cónico; los espigones, extremadamente estrechos en comparación con su gran altura para dar sensación de verticalidad; las antefijas, elementos más pequeños tomados de su homólogo clásico, originalmente situadas delante de las tejas y las acróteras también de origen clásico, situadas preferentemente en los laterales.

Debe tenerse en cuenta una circunstancia: como se ha indicado, el remate de cubierta presenta una gran variedad de diseños y esto a veces provoca que presente elementos comunes a estos otros diseños que acaban de nombrarse. Además, dentro de los remates de cubierta, también se encuentran agrupamientos con características similares, como son: el diseño en esfera (figura 2, izqda.), que suelen situarse sobre un pequeño pedestal de molduras; la forma voluminosa que se estrecha en su parte superior y termina generalmente en un capullo rodeada 
de motivos vegetales, a modo de jarrón cerrado (figuras 2 , dcha.) y el diseño en capullo sobre pedestal con hojas que se abren para mostrar una forma ovoide (figura 3). Evidentemente también sin pertenecer a ningún agrupamiento se encuentran otros diseños de originales formas, que mostraremos más adelante, o estas mismas con ciertas variaciones.

Los diseños pueden ubicarse a lo largo de la cubierta, o bien delimitarla en sus extremos, pero puede darse un caso intermedio que consiste en repartirlos por toda la línea superior, pero diferenciando mediante distinta escala los centrales de los laterales, estos últimos más importantes por encuadrar la fachada, ubicados generalmente en línea con las pilastras inferiores.
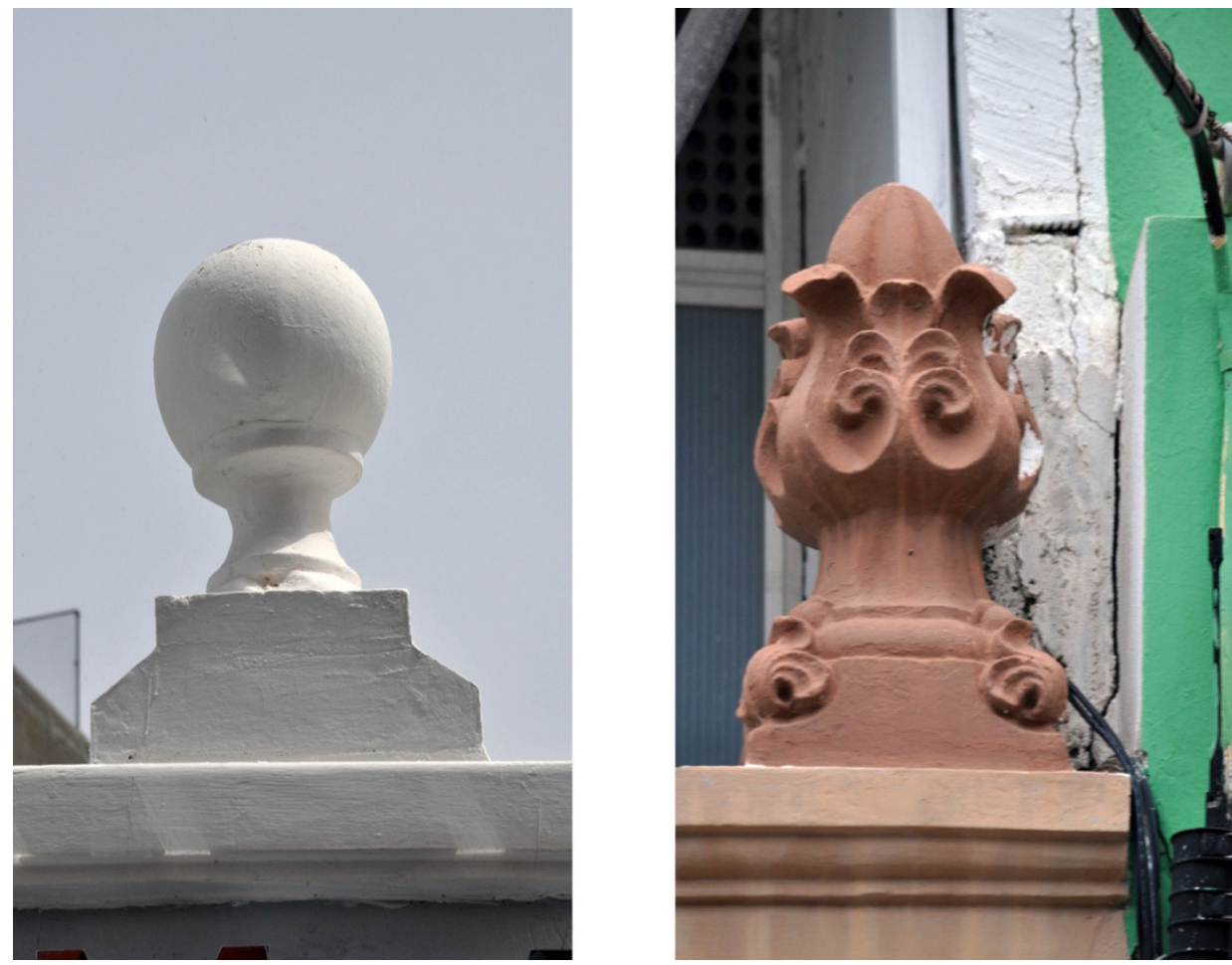

Figura 2. Remate de cubierta en esfera del edificio de la calle Emilio López no 40 de Santa Cruz de Tenerife (izquierda). Figura 2 derecha. Remate de cubierta en capullo del edificio $\mathrm{n}^{\mathrm{o}} 137$ de la carretera Punta del Hidalgo TF-13, Tenerife (derecha). Fotos: José Antonio

Sabina González.

Como se ha apuntado anteriormente, la idea de colocar un elemento decorativo de esta índole realmente es fruto de inspiraciones externas a las islas. Estas formas ornamentales las encontramos en otros lugares, con diseños similares como podemos ver en el ejemplo de la figura 3. 


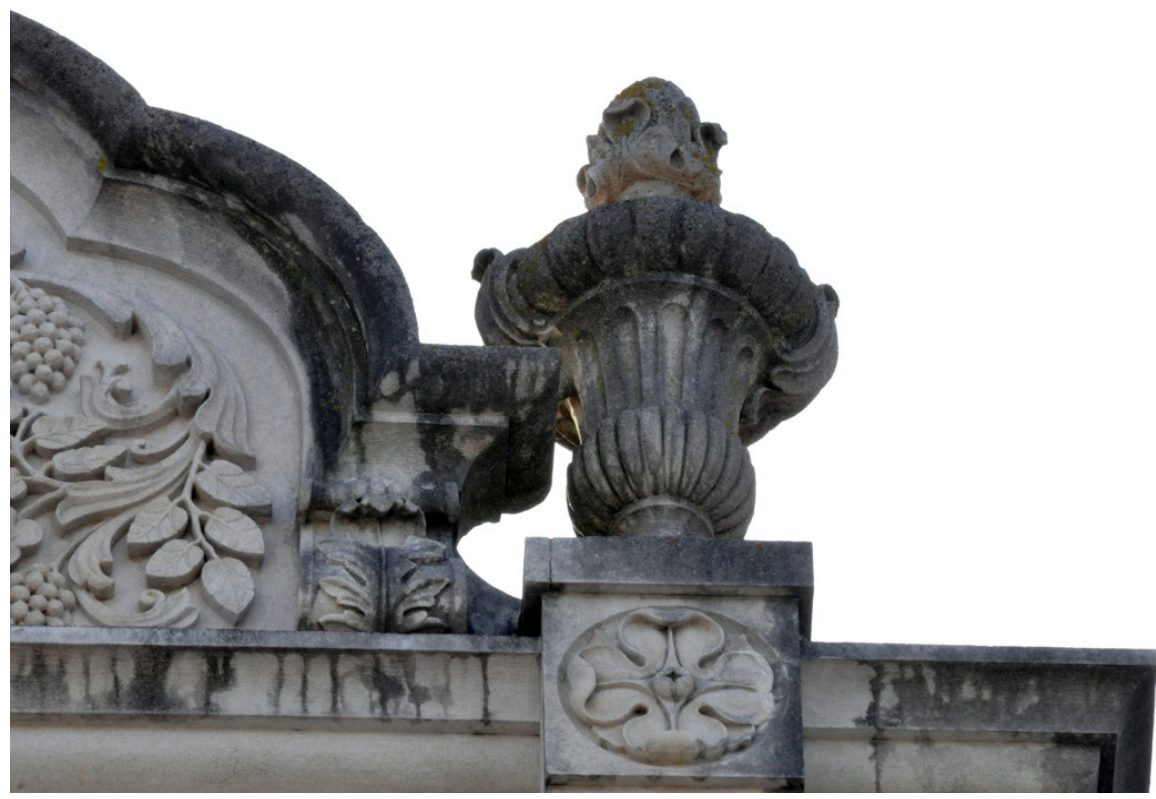

Figura 3. Remate de cubierta del edificio n. ${ }^{\circ} 15$ de la avenida Emídio Navarro de Coímbra, Portugal. Foto: José Antonio Sabina González.

\section{REPRESENTACIÓN GRÁFICA: LOS TECNICOS}

Una vez expuesto el elemento decorativo estudiado, pasamos a tratar a los legítimos responsables de la incorporación de este ornato en las fachadas: los técnicos. Los expedientes de petición de licencia constructiva localizados con el detalle decorativo estudiado en sus planos lo incluimos en las tablas siguientes, ordenados cronológicamente por cada técnico como se ha indicado, para mostrar su evolución ornamental, y se añaden datos adicionales como la dirección que figura en ellos.

Se incluye la fecha que presentan, pero debe indicarse que el momento real de la elaboración puede ser un poco antes, aunque suele coincidir con el que figura en el plano si la tiene. Así también subrayamos que no estamos incluyendo los demás elementos de clasificación aparte ya puntualizados, como jarrones, pináculos y demás, ocupándonos únicamente del remate de cubierta descrito; aunque puede ocurrir que se encuentre además de él, algún otro de estos elementos en el mismo plano.

Comenzamos el análisis partiendo de los técnicos que más escasamente han utilizado el elemento decorativo tratado. 


\subsection{Manuel de Cámara y Cruz}

Manuel de Cámara, arquitecto cuya ciudad natal fue Santa Cruz de Tenerife, tuvo una trayectoria profesional que le llevó a diseñar el plano de ensanche para la Sociedad de Edificaciones y Reformas Urbanas (DARIAS, 1985: 140-141). Además, ocupó el cargo de arquitecto diocesano, funciones que no le impidieron mantener sus aficiones como la elaboración de artículos o la política (DARIAS, 1985: 132, 133, 134).

En sus impresionantes edificios no se escatiman recursos decorativos, lo cual demuestra una inventiva asombrosa cuando los límites no los acota la economía de su propietario, como señala Darias cuando comenta sobre Cámara, en caso contrario impera la sencillez (DARIAS, 1985: 144), pero no ocurre así en estos edificios.

TABLA 1

Edificios de Manuel de Cámara que incluyen remates de cubierta

\begin{tabular}{|c|c|c|c|c|c|}
\hline $\begin{array}{c}\mathbf{N}^{\mathbf{0}} \\
\text { orden }\end{array}$ & $\begin{array}{c}\text { Archivo } \\
\text { Municipal }\end{array}$ & Expediente & Dirección & $\begin{array}{c}\text { Tipología } \\
\text { Lenguaje }\end{array}$ & $\begin{array}{c}\text { Año } \\
\text { Licencia }\end{array}$ \\
\hline 1 & S/C Tenerife & $\begin{array}{c}\text { Ud. Instal } \\
494 / 28\end{array}$ & $\begin{array}{c}\text { Calle San Lucas junto a la } \\
\text { iglesia del Pilar }\end{array}$ & Ecléctico & 1896 \\
\hline 2 & S/C Tenerife & $\begin{array}{c}\text { Ud. Instal } \\
7 / 56\end{array}$ & $\begin{array}{c}\text { C/ Bethencourt Alfonso } \\
\text { esquina con C/ de San } \\
\text { Francisco }\end{array}$ & Ecléctico & 1901 \\
\hline
\end{tabular}

El edificio n. ${ }^{\circ}$ 1, dedicado a la comunidad del Sagrado Corazón de María junto a la iglesia del Pilar, Cámara incorpora nuestro elemento sobre el antepecho de cubierta de un impresionante inmueble de tres plantas y cubierta de gran importancia decorativa. El estilo del diseño del remate que estudiamos sigue la línea de la figura 1, con un nivel de detalle muy aceptable. Sobre el antepecho del balcón de la planta inferior esboza otro remate más pequeño, sencillo y esbelto.

Su siguiente edificio n. ${ }^{\circ} 2$ no se queda atrás; se trata del torreón Ascanio, en el que Cámara vuelve a utilizar el antepecho de cubierta para ubicar el ornato con otro diseño de la misma línea pero con la parte voluminosa más próxima a una esfera que a una copa, es diferente pero igualmente atractivo. Le dedica gran minuciosidad, más que a otros elementos como al acabado del antepecho que se muestra en la figura 4 izquierda. Al igual que el edificio anterior, si lo ubica en una planta más baja, como el antepecho del balcón de la planta segunda, le aumenta su esbeltez, por lo que se acerca más a un pináculo. De todas formas, para Darias, los pináculos de Cámara solo están presentes en casos excepcionales y poniendo como ejemplo el torreón Ascanio, adoptan formas circulares y por tanto no son auténticos pináculos (DARIAS, 1985: 148).

Con respecto a la relación del remate con la fachada, en el edificio n. ${ }^{\circ} 2$ existe una inspiración formal entre dos zonas, y es que en la ubicación más lógica para situar un espigón, la parte superior de la bóveda peraltada, Cámara opta por representar un elemento menos esbelto, como nuestro remate, de formas muy similares al que ubica en la cubierta pero a una escala superior debido a la lejanía; 
y luego, como se ha comentado un tercer remate más próximo a un pináculo en el balcón inferior. Debe añadirse que finalmente al edificio construido se le añadió una gran aguja al remate de la bóveda.

Para concluir, en ambos edificios queda latente una predilección por las partes bajas y más concretamente en los balcones para situar los remates más esbeltos y de menores dimensiones, y las partes altas los mayores, pero menos esbeltos.
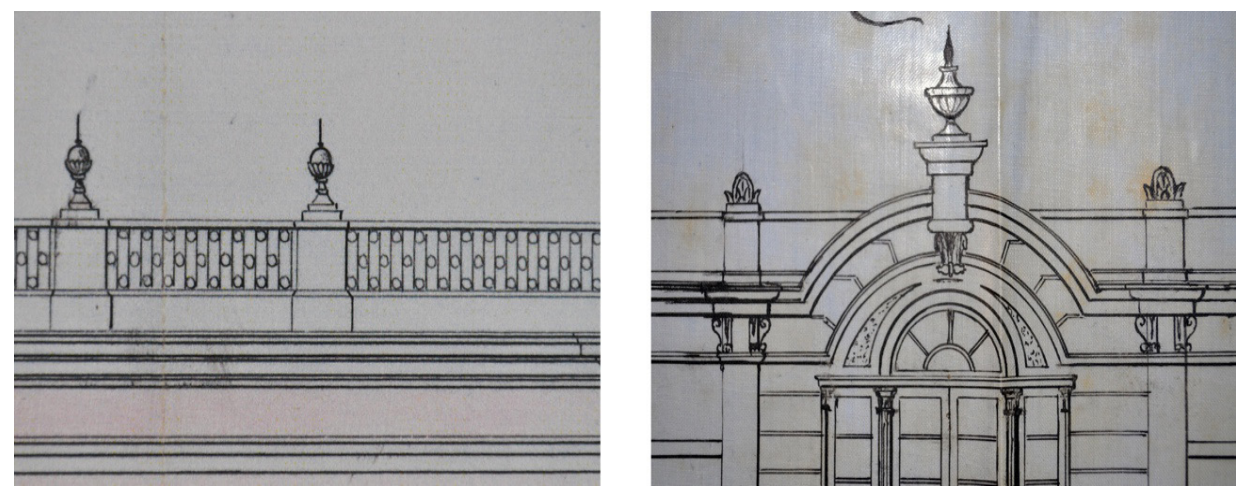

Figura 4. Remate de cubierta. Ornato público. Unid. de Instal 7-56. Archivo Municipal S/C TFE. Arqto. Manuel de Cámara (izquierda). Remate de cubierta. Ornato público. Legajo 06 n¹32/1. Archivo Municipal del Puerto de la Cruz. Apaj. Antonio Martín (derecha). Fotos: José Antonio Sabina González.

\subsection{Antonio Martín Núñez}

Antonio Martín Núñez (1847-1931), fue aparejador municipal del Puerto de la Cruz. Los aparejadores podían proyectar si el presupuesto de obras, no se excedía de las 10.000 pesetas de entonces, a falta de arquitecto, como Eduardo Zalba ha indagado. Este técnico realizó funciones de perito, diseño de planos para proyectos municipales y particulares, y director responsable en algunas obras (ZALBA, 2009: 321-232). Su estilo obedecía a tintes eclécticos con decoración en molduras por toda la fachada (ZALBA, 2008: 142). 
TABLA 2

Edificios de Antonio Martín Núñez que incluyen remates de cubierta

\begin{tabular}{|c|c|c|c|c|c|}
\hline $\begin{array}{c}\mathbf{N}^{\circ}{ }^{\circ} \\
\text { orden }\end{array}$ & $\begin{array}{c}\text { Archivo } \\
\text { Municipal }\end{array}$ & Expediente & Dirección & $\begin{array}{c}\text { Tipología } \\
\text { Lenguaje }\end{array}$ & $\begin{array}{c}\text { Año } \\
\text { Licencia }\end{array}$ \\
\hline 3 & $\begin{array}{c}\text { Puerto de la } \\
\text { Cruz }\end{array}$ & $\begin{array}{c}\text { Legajo 05 n. } \\
131 / 32\end{array}$ & C/ D. Luis de la Cruz n. ${ }^{\circ}$ 6 & Ecléctico & 1915 \\
\hline 4 & $\begin{array}{c}\text { Puerto de la } \\
\text { Cruz }\end{array}$ & $\begin{array}{c}\text { Legajo 06 n. } .^{\circ} \\
132 / 1\end{array}$ & $\begin{array}{c}\text { C/ de la Marina n. }{ }^{\circ} \text { 1, Plaza } \\
\text { de la Constitución n. } \\
\text { de Perdomo } \text { n. }^{\circ} \text { 2 }\end{array}$ & Ecléctico & 1918 \\
\hline
\end{tabular}

Los dos ejemplos de Martín localizados corresponden a los números 3 y 4 . El primero de ellos denota la gran importancia que da este autor a la decoración, por el ornato que presenta la fachada en general y por lo minucioso de sus detalles, pues hasta traza las lineas de cada balaustre, pero si es verdad que en general se advierte cierta falta de precisión aunque debe recordarse que se elaboran a mano alzada. El remate lo sitúa sobre el antepecho de cubierta, haciéndolo coincidir con las pilastras de la planta inferior al prolongarlas a modo de pedestal en dicho antepecho. En el diseño también sigue la línea de la figura 1, pero con la parte más voluminosa en forma de esfera con franjas verticales. Realiza una distinción en tamaño: los remates laterales son de mayor dimensión que los dos centrales.

El siguiente edificio número 4 y último de Martín, también utiliza la misma ubicación para situar el remate. Se trata de una remodelación de fachada, ocultando las tejas con un antepecho para simular una azotea sobre el cual se presentan nuestros elementos. Esta práctica fue muy habitual, sobre todo en La Laguna para adatarse a las nuevas tendencias estéticas arquitectónicas. Darias nos indica cómo en esta época, esta ciudad se concentró en la restauración de las casas, dejando de lado las nuevas construcciones (DARIAS, 1991: 24). Martín utiliza dos diseños para representar el remate de cubierta también con el estilo de la figura 1: uno con forma de copa mostrado en la figura 4 derecha y el otro en esfera, ambos situados sobre la clave del arco de cubierta de dos pórticos principales de entrada. Estos diseños están flaqueados por otros dos remates más pequeños con forma de tres hojas, la central más grande, que además se repiten a lo largo del antepecho sobre pilastra corta a modo de pedestal. La hoja central de este último diseño recuerda a las antiguas antefijas. En general, Martín sigue definiendo bastante los detalles, aunque con cierta falta de precisión salvo en este caso los remates de cubierta que están muy bien conseguidos.

La relación del remate dentro del conjunto de la fachada que muestra Martín denota una predilección por la cubierta. En ambos edificios de dos plantas a pesar de contar con balcón inferior, este no se destina a albergar el remate, Martín prefiere el lugar más destacado: si el edificio opta por una entrada principal de tal importancia que involucre la planta siguiente y que invada la cubierta como ocurre con el edificio n. ${ }^{\circ} 4$ de la figura 4 derecha con un arco, el remate lo sitúa sobre la clave del mismo. En caso de que la decoración de la entrada no se amplíe a la cubierta, Martín corona la totalidad del antepecho de la misma con remates sobre pilaretes, que son prolongación de las pilastras del nivel inferior. Es decir, podemos hablar de una predilección por la zona más alta, y dentro de ella el lugar más destacado. 


\subsection{Otilio Arroyo Herrera}

Otilio Arroyo, arquitecto que nació en Santa Cruz de Tenerife y que partió a Barcelona para realizar parte de su carrera, fue excepcional en sus estudios. Destacó además por su honradez, pero se vio envuelto en algunas discusiones durante su vida profesional (Darias, 1985: 365, 366, 368).

TABLA 3

Edificios de Otilio Arroyo que incluyen remates de cubierta

\begin{tabular}{|c|c|c|c|c|c|}
\hline $\begin{array}{l}\mathrm{N} .{ }^{\circ} \\
\text { orden }\end{array}$ & $\begin{array}{l}\text { Archivo } \\
\text { Municipal }\end{array}$ & Expediente & Dirección & $\begin{array}{l}\text { Tipología } \\
\text { Lenguaje }\end{array}$ & $\begin{array}{c}\text { Año } \\
\text { Licencia }\end{array}$ \\
\hline 5 & S/C de Tenerife & Ud. Instal 24/27 & $\begin{array}{l}\text { Plaza de la Iglesia } \\
\text { n. }{ }^{\mathrm{O}} 13\end{array}$ & Ecléctico & 1924 \\
\hline 6 & S/C de Tenerife & Ud. Instal 76/93 & $\begin{array}{c}\text { C/ Imeldo Serís n. } \\
11,13 \text { y } 15\end{array}$ & Ecléctico & 1926 \\
\hline
\end{tabular}

En el primer edificio número 5 de Arroyo que destaca por la cantidad de molduras y cenefas que presenta, utiliza el dintel de la puerta de balcón para situar los remates. Realmente el dintel simula a un entablamento griego sobre columnas corintias pero sin el friso, sino solo con arquitrabe y cornisa, y sobre ella en los laterales sitúa nuestro elemento estudiado. Utiliza un diseño innovador a base de dos pequeñas copas sobre diversas molduras que flanquean la decoración central en festón del dintel. En este caso reserva el antepecho de cubierta para ubicar unos atractivos jarrones. Darias indica como la arquitectura de Arroyo suele ser pobre por dedicarse a las clases menos pudientes (Darias, 1985: 370) pero en este edificio, que lo protagoniza el ornato no puede calificarse así.

En el segundo edificio número 6 de Arroyo, una remodelación de fachada, repite el estilo delgado en sus remates de cubierta, con solo una copa cerrada en este caso pero con más molduras que la preceden. El antepecho es la ubicación elegida en este caso y como la delgadez del ornato puede parecer al autor escasa para ubicarlo solo, los agrupa de tres en tres, que mostramos en la figura 5 izquierda, en la parte central de la fachada.

La relación del remate dentro del conjunto de la fachada denota cierto empequeñecimiento. En el edificio n. ${ }^{\circ} 5$ su presencia es casi inapreciable, tanto por sus reducidas dimensiones y esbeltez, como por la abundante decoración del resto de elementos decorativos que desvían la atención. De forma similar ocurre en el edificio n. ${ }^{\circ} 6$, un imponente inmueble cuyo remate, a pesar de ocupar un lugar destacado de la cubierta, Arroyo opta por su acostumbrada estrechez en ellos. Para compensarlo, el arquitecto agrupa tres remates juntos, lo cual no deja de ser una singularidad, junto con lo peculiar de su ubicación, pues elige la parte central de la cubierta, ya que si no se reparten por ella lo normal es posicionarlos en los laterales. De todas maneras, con esta nueva posición el arquitecto consigue destacar el vano central donde se sitúa la puerta principal del edificio, aumentando la sensación de verticalidad y altura. 

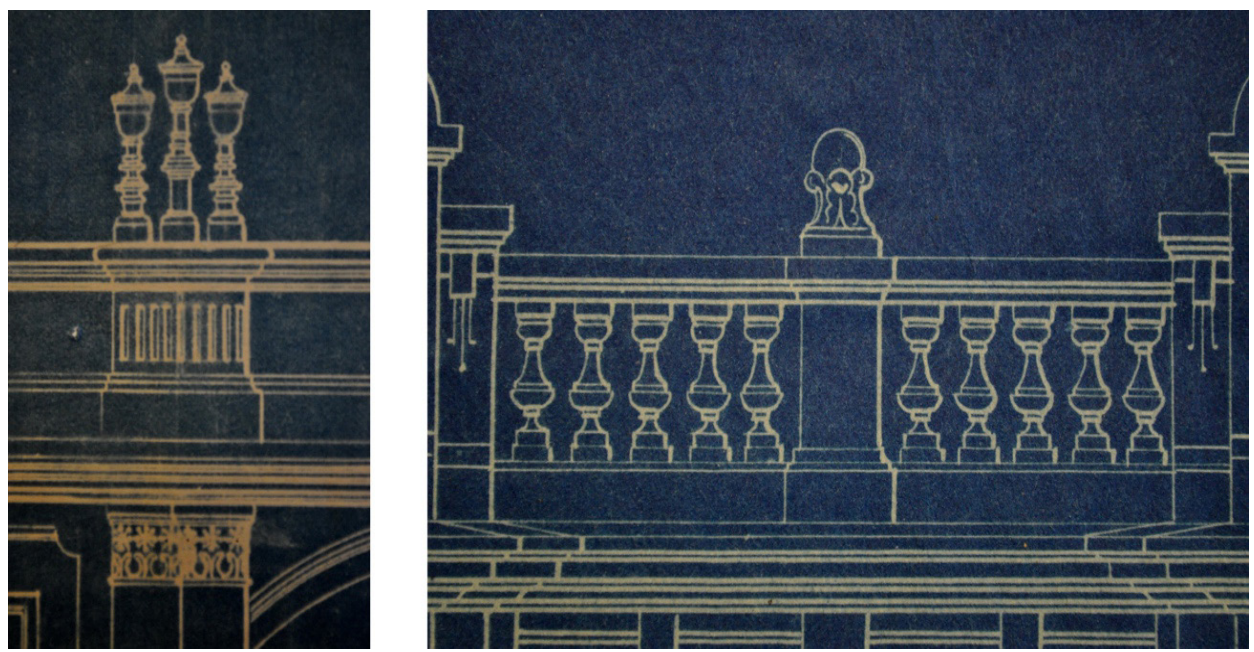

Figura 5. Remate de cubierta. Ornato público. Unid. de Instal 76-93. Archivo Municipal S/C TFE. Arqto. Otilio Arroyo (izquierda). Remate de cubierta. Ornato público. Unid. de Instal 75-14. Archivo Municipal S/C TFE. Arqto. Pelayo López (derecha). Fotos: José Antonio Sabina González.

\subsection{Pelayo López y Martín Romero}

Pelayo López y Martín nació en Santa Cruz de La Palma y estuvo establecido en Madrid y Tenerife, realizando su carrera profesional en la Escuela Superior de Arquitectura de Barcelona. Sus tendencias decorativas quedaron demostradas cuando se le encargó un proyecto para Las Palmas (DARIAS, 1985: 345-346).

TABLA 4

Edificios de Pelayo López y Martín que incluyen remates de cubierta

\begin{tabular}{|c|c|c|c|c|c|}
\hline $\begin{array}{c}\mathbf{N}^{\mathbf{}} \\
\text { orden }\end{array}$ & $\begin{array}{c}\text { Archivo } \\
\text { Municipal }\end{array}$ & Expediente & Dirección & $\begin{array}{c}\text { Tipología } \\
\text { Lenguaje }\end{array}$ & $\begin{array}{c}\text { Año } \\
\text { Licencia }\end{array}$ \\
\hline 7 & $\begin{array}{c}\text { S/C de } \\
\text { Tenerife }\end{array}$ & $\begin{array}{c}\text { Ud. Instal } \\
75 / 14\end{array}$ & $\begin{array}{c}\text { C/ Imeldo Serís n. } \\
57 \text { y } 59\end{array}$ & Ecléctico & 1926 \\
\hline 8 & $\begin{array}{c}\text { S/C de } \\
\text { Tenerife }\end{array}$ & $\begin{array}{c}\text { Ud. Instal } \\
77 / 115\end{array}$ & $\begin{array}{c}\text { C/ Imeldo Serís n. }{ }^{\circ} 11, \\
13 \text { y 15 }\end{array}$ & Ecléctico & 1926 \\
\hline
\end{tabular}


En el primer ejemplo número 7, Pelayo opta por el típico diseño en esfera de la figura 2 izquierda pero su base no es un pedestal con molduras, sino que en este atractivo diseño la esfera se apoya sobre hojas que se curvan hacia el exterior, a modo de perla como puede comprobarse en la figura 5 derecha. Lo ubica sobre el antepecho de la última planta, su lugar habitual como hemos ido comprobando, entre coronaciones de cubierta que coinciden con las pilastras de orden gigante de las plantas inferiores.

En el caso del siguiente ejemplo número 8 y último, Pelayo opta por variar el diseño al estilo en copa cerrada de la figura 1. El antepecho de cubierta vuelve a ser la zona elegida, sobre un pedestal con decoración en caída de ornato, en línea con las pilastras inferiores menos los dos remates de cubierta centrales. La cornisa divide la continuidad entre pilastra y pedestal.

En ambos edificios de aspecto similar e igual n. ${ }^{\circ}$ de plantas, queda plasmado el estilo de Martín sobre nuestro ornato, cuya ubicación es exclusiva del antepecho de cubierta. Si el remate sigue la línea de las pilastras, se acentúa la verticalidad del edificio con la esbeltez moderada que proporciona el diseño en copa de cerrada de la figura 1, a modo de culminación de las mismas. Si acaso el remate no continúa a las pilastras, porque se prefiere rematarlas con otro complemento, como con una coronación de cubierta, Martín achata el remate con un diseño que reduzca esbeltez, como la forma en perla de la figura 5 derecha. En este segundo caso, el arquitecto prefiere aportar la verticalidad mediante el recurso de las pilastras de orden gigante.

\subsection{Mariano Estanga y Arias Girón}

A continuación tratamos cuatro edificios de Mariano Estanga ubicados en La Laguna y La Orotava. Este arquitecto nació en Valladolid, estudió en la Escuela Superior de Arquitectura de Madrid y finalmente se afincó en Tenerife, donde realizó proyectos de edificios de estilo modernista y ecléctico (DARIAS, 1985: 315).

TABLA 5

Edificios de Mariano Estanga que incluyen remates de cubierta

\begin{tabular}{|c|c|c|c|c|c|}
\hline $\begin{array}{c}\mathbf{N}^{\mathbf{0}} \\
\text { orden }\end{array}$ & $\begin{array}{c}\text { Archivo } \\
\text { Municipal }\end{array}$ & Expediente & Dirección & $\begin{array}{c}\text { Tipología } \\
\text { Lenguaje }\end{array}$ & $\begin{array}{c}\text { Año } \\
\text { Licencia }\end{array}$ \\
\hline 9 & La Laguna & Ud. Instal 599/44 & C/ San Agustín & Ecléctico & 1910 \\
\hline 10 & La Orotava & Ud. Instal 22/60 & C/ Verde & Ecléctico & 1913 \\
\hline 11 & La Orotava & Ud. Instal 134/27 & C/ La Carrera & Ecléctico & 1920 \\
\hline 12 & La Orotava & Ud. Instal 23/17 & $\begin{array}{c}\text { Plaza de la } \\
\text { Constitución }\end{array}$ & Ecléctico & 1924 \\
\hline
\end{tabular}

Su primer edificio número 9, obra de reforma de fachada, destaca por la decoración de la cubierta, especialmente en la decoración central, cuyo 
impresionante ornato de roleos rodea las iniciales de su propietario. En este edificio los verdaderos protagonistas son los pináculos y jarrones del antepecho de cubierta, en el que nuestro remate también se encuentra tímidamente en los laterales del edificio. El diseño sencillo muestra una forma esférica, del estilo de la figura 2 izquierda pero sobre un pedestal semirredondo más elaborado. En este edificio se mantiene la afirmación de Darias sobre la alternancia de tramos abalaustrados con ciegos de Estanga en sus coronamientos, y la decoración simple en rectángulos que incluye en estos últimos, además de sus jarrones de boca ancha (DARIAS, 1985: 318-319).

Seguidamente comentamos el edificio número 10, un inmueble de corte religioso en el que Estanga vuelve al diseño sencillo en esfera del remate anterior ubicado en la cubierta, pero le aporta un pedestal en franjas verticales de considerable altura siguiendo el recorrido de las pilastras inferiores para aportar verticalidad a un inmueble de una planta.

Con respecto al siguiente edificio número 11, Estanga vuelve a repetir el diseño esférico, pero con forma de huevo sobre un pedestal en molduras ubicado en los laterales del antepecho de cubierta. Destaca el grosor de este pedestal en comparación con la escala del remate.

Y por último el expediente número 12 de Estanga, en el que sorprendentemente se incluyen varios remates distintos repartidos por todo el antepecho de cubierta de tres casas, además del jarrón de boca ancha que indicaba Darias. Estos diseños se basan en la copa cerrada de franjas verticales y perlas mostrado en la figura 6 izquierda sobre un impresionante pedestal de roleos, urnas de roleos laterales en capullo del estilo de la figura 2 derecha y en algunos casos sobre grandes bases decoradas con ornatos vegetales.

La pauta que sigue Estanga en relación a la fachada y que mostramos en la figura 6 izquierda, es un ejemplo tipo. Denota un gusto por la combinación de elementos altos y bajos, en edificios preferentemente de dos alturas. Los primeros son nuestros remates y los segundos jarrones, en este caso, pero puede optarse por una combinación en la que el elemento alto lo forman pináculos y el bajo remates. Se concede una importancia crucial al pedestal, equiparable al propio remate, como puede comprobarse en la figura 6 izquierda, para aumentar la altura del mismo y aportar sensación de verticalidad y es que dentro del conjunto de la fachada dicho pedestal aporta cierto protagonismo a nuestro remate. 

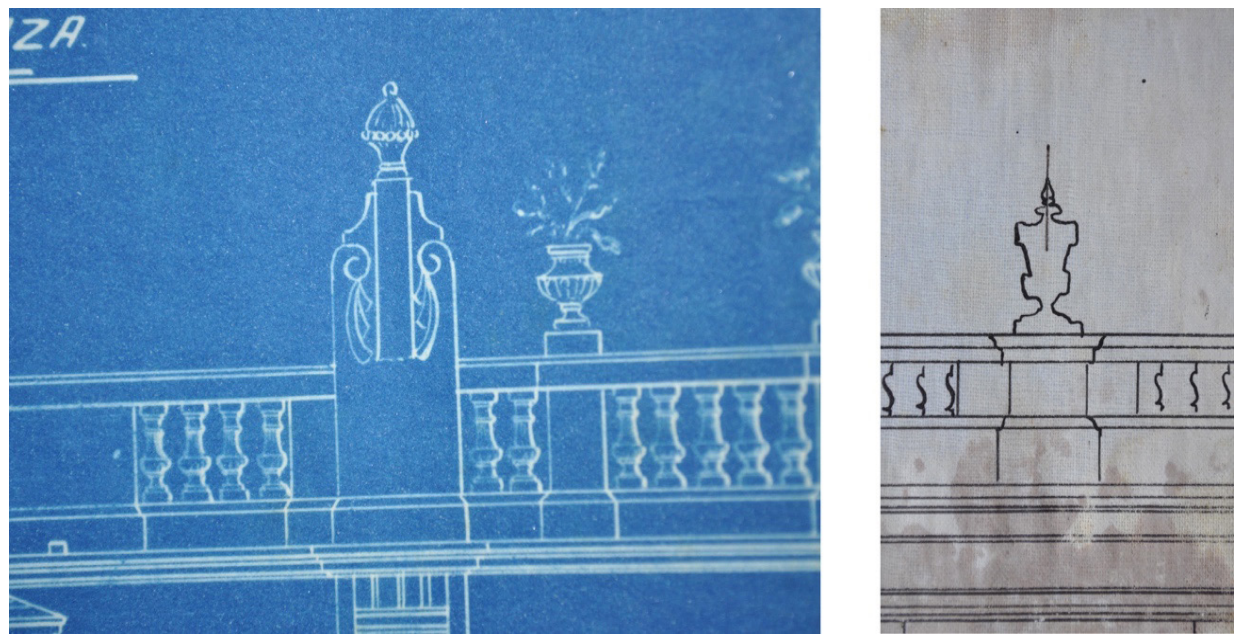

Figura 6. Remate de cubierta. Ornato público. Unid. de Instal 23-17. Archivo Municipal de La Orotava. Arqto. Mariano Estanga (izquierda). Remate de cubierta. Ornato público. Unid. de Instal 607-1. Archivo Municipal de La Laguna. Arqto. Javier Felíp Solá. Fotos: José Antonio Sabina González.

\subsection{Javier Felip Solá}

Siguiendo el orden establecido tratamos ahora a Javier Felip Solá con ocho edificios. Solá fue arquitecto municipal del Puerto de la Cruz entre 1926 y 1927, pasándose finalmente a ocupar este puesto en San Cristóbal de La Laguna.

TABLA 6

Edificios de Javier Felip Solá que incluyen remates de cubierta

\begin{tabular}{|c|c|c|c|c|c|}
\hline $\begin{array}{l}\mathrm{N}^{\circ} \\
\text { orden }\end{array}$ & $\begin{array}{l}\text { Archivo } \\
\text { Municipal }\end{array}$ & Expediente & Dirección & $\begin{array}{l}\text { Tipología } \\
\text { Lenguaje }\end{array}$ & $\begin{array}{c}\text { Año } \\
\text { Licencia }\end{array}$ \\
\hline 13 & $\begin{array}{l}\text { Puerto de la } \\
\text { Cruz }\end{array}$ & $\begin{array}{c}\text { Legajo } 07 \text { n. } \\
\text { 133/39 }\end{array}$ & $\begin{array}{l}\text { C/ Cupido n. }{ }^{\circ} 3 \text { y c/ } \\
\text { Nieves Ravelo n. }{ }^{\circ} 17\end{array}$ & Ecléctico & 1926 \\
\hline 14 & $\begin{array}{l}\text { Puerto de la } \\
\text { Cruz }\end{array}$ & $\begin{array}{c}\text { Legajo } 07 \text { n. }^{\circ} \\
133 / 42 \\
\end{array}$ & $\begin{array}{l}\text { C/ Quintana y plaza } \\
\text { del Dr Victor Pérez }\end{array}$ & Ecléctico & 1926 \\
\hline 15 & $\begin{array}{l}\text { Puerto de la } \\
\text { Cruz }\end{array}$ & $\begin{array}{l}\text { Legajo } 07 \mathrm{n}^{\circ} \\
\text { 133/44 }\end{array}$ & $\begin{array}{l}\text { C/ Quintana y plaza } \\
\text { del Dr Victor Pérez }\end{array}$ & Ecléctico & 1926 \\
\hline 16 & $\begin{array}{c}\text { Puerto de la } \\
\text { Cruz }\end{array}$ & $\begin{array}{c}\text { Legajo } 08 \text { n. }^{\circ} \\
134 / 5\end{array}$ & $\begin{array}{l}\text { C/ Cupido y c/ Nieves } \\
\text { Ravelo }\end{array}$ & Ecléctico & 1927 \\
\hline 17 & La Laguna & Ud. Instal 607/1 & $\begin{array}{c}\text { Paseo de la } \\
\text { Universidad esquina } \\
\text { con Avenida de } \\
\text { Tabares Bartlett }\end{array}$ & Ecléctico & 1927 \\
\hline
\end{tabular}




\begin{tabular}{|c|c|c|c|c|c|}
\hline 18 & La Orotava & Ud. Instal 23/67 & C/ del Loro & Ecléctico & 1927 \\
\hline 19 & La Laguna & Ud. Instal 611/46 & $\begin{array}{c}\text { Carretera Tejina - } \\
\text { Punta del Hidalgo km } \\
\text { 3, Hm 2 }\end{array}$ & Ecléctico & 1931 \\
\hline 20 & La Laguna & Ud. Instal 611/45 & $\begin{array}{c}\text { Carretera Tejina - } \\
\text { Punta del Hidalgo km } \\
\text { 3, Hm 2 }\end{array}$ & Ecléctico & 1931 \\
\hline
\end{tabular}

En el primer edificio número 13 de Solá, al igual ocurrió con Estanga, presenta alternancia de pináculos con remates en esfera, similares al mostrado en la figura 2 izquierda pero con diseños más sencillos y sin decoración orgánica. Solá demuestra un estilo de representación muy esquemático, no detalla salvo su perímetro, prefiere insinuar las formas. Tampoco reserva los pináculos para edificios de cierto número de plantas, sino que no tiene problema en utilizarlo en un inmueble de una planta sola. Los pináculos los ubica en las esquinas y el remate en esfera equidistantemente colocado en la parte central. Todos sobre el antepecho de la cubierta.

En su siguiente edificio número 14 de remodelación de fachada, se vuelve al diseño sencillo en esfera anterior, pero en este caso los coloca en los laterales del antepecho de la cubierta y sobre el pórtico de entrada de las puertas principales. Un pórtico inspirado en los entablamentos clásicos con arquitrabe y cornisa sobre columnas corintias. En el diseño se vuelve a representar solo el perfil del elemento, en un plano en la línea de Solá de emular las formas más que definirlas, al menos lo que requiera elaboración a mano alzada.

Con respecto al siguiente edificio número 15 el arquitecto sigue la pauta del edificio anterior, con el mismo diseño en esfera de la figura 3, pero ahora lo repite a lo largo y sobre el antepecho de cubierta salvo en los laterales en los que opta por colocar el otro diseño en copa cerrada similar a la figura 1. Debe indicarse que se trata del edificio anterior en el que se ha optado por realizar ciertas modificaciones. En todos vuelve a delimitar solo el contorno del remate, salvo en la parte central de este último que excepcionalmente traza un festón poco definido que lo envuelve.

Otro avance muestra en el siguiente edificio número 16, en el que a pesar de volver a su típico diseño en esfera ya nombrado ahora no solo marca su contorno, sino que también los detalles internos que en este caso son las molduras de su base. Todos están situados en las esquinas y sobre el antepecho de cubierta. Se vuelve a repetir la modificación de planos de un expediente anterior, pues es el mismo edificio n. ${ }^{\circ} 13$.

A continuación, en el edificio número 17 cambia el diseño en esfera anteriormente apuntado por la copa cerrada que incluimos en la figura 6 derecha. Lo vuelve a ubicar sobre el antepecho de cubierta, sobre pedestal y con la misma pauta de marcar solamente su perímetro y en este caso su eje. En el pórtico de entrada vuelve a recurrir a su entablamento clásico pero sin remates, porque ubica un frontón sobre la cornisa.

En la reconstrucción del edificio número 18, en el que ya contamos con dos plantas, el arquitecto incorpora pináculos en los laterales y su típico diseño sencillo en esfera en la parte central. Todos están también sobre el antepecho de cubierta, 
sobre pedestal, y en este caso no solo traza su perímetro, sino que también los trazos internos de todos.

En el caso del edificio número 19, Solá vuelve a optar por su acostumbrado diseño simple en esfera en los laterales y sobre el antepecho de cubierta. El diseño incorpora sus trazos internos en un plano con más definición de formas, salvo los motivos vegetales del alfeizar de las ventanas, más informales. Lo comentado anteriormente se repite en su último edificio número 20. Ambos inmuebles son iguales, pero con otro propietario.

Se puede decir que los remates de Solá imperan mayormente en edificios de una planta, con un volumen de cierta importancia con respecto al resto de componentes, que puede reducirse un poco cuando opta por el diseño sencillo en esfera y que no suelen presentarse de forma aislada, sino que se reparten por todo el antepecho de cubierta. En la línea de esto último es muy común en este arquitecto reservar las esquinas laterales del inmueble para los remates más voluminosos, y los menos como el mencionado diseño en esfera para el resto del antepecho.

\subsection{Domingo Pisaca Burgada}

Domingo Pisaca, natal de Santa Cruz de Tenerife, se formó en la Escuela Técnica Superior de Arquitectura de Barcelona, una institución en la que se daba gran importancia al lenguaje modernista, como es conocido. A pesar de ello, Pisaca recurrió durante mucho tiempo al estilo ecléctico que empleó en una cantidad importante de edificios en los que el ornato es el protagonista de la fachada y posteriormente, a partir de 1930 comienza a introducirse en el lenguaje racionalista (DARIAS, 1985: 382, 384, 385). Se han localizado muchos edificios que cuentan con el remate de cubierta, concretamente con 44, por lo que se ha optado por agruparlos por años para su estudio.

TABLA 7

Edificios de Domingo Pisaca que incluyen remates de cubierta

\begin{tabular}{|c|c|c|c|c|c|}
\hline $\begin{array}{l}\mathrm{N} .{ }^{\circ} \\
\text { orden }\end{array}$ & $\begin{array}{l}\text { Archivo } \\
\text { Municipal }\end{array}$ & Expediente & Dirección & $\begin{array}{l}\text { Tipología } \\
\text { Lenguaje }\end{array}$ & $\begin{array}{c}\text { Año } \\
\text { Licencia }\end{array}$ \\
\hline 21 & S/C de Tenerife & $\begin{array}{l}\text { Ud. Instal } \\
44 / 38\end{array}$ & $\begin{array}{c}\text { Rambla del General } \\
\text { Franco n. } 59 \text { esquina } \\
\text { con c/ General Ramos } \\
\text { Serrano n. } .^{\circ} 1\end{array}$ & Ecléctico & 1921 \\
\hline 22 & S/C de Tenerife & $\begin{array}{l}\text { Ud. Instal } \\
41 / 68\end{array}$ & $\begin{array}{l}\text { Finca Llanos de San } \\
\text { Sebastián, alineación } \\
\text { oeste de c/ Los Molinos }\end{array}$ & Ecléctico & 1922 \\
\hline 23 & S/C de Tenerife & $\begin{array}{l}\text { Ud. Instal } \\
30 / 28\end{array}$ & Rambla de Pulido n. ${ }^{\circ} 17$ & Ecléctico & 1923 \\
\hline 24 & $\mathrm{~S} / \mathrm{C}$ de Tenerife & $\begin{array}{l}\text { Ud. Instal } \\
30 / 7\end{array}$ & $\begin{array}{c}\text { Camino de los Coches } \\
\text { n. }{ }^{\circ} 11\end{array}$ & Ecléctico & 1923 \\
\hline
\end{tabular}




\begin{tabular}{|c|c|c|c|c|c|}
\hline 25 & $\mathrm{~S} / \mathrm{C}$ de Tenerife & $\begin{array}{l}\text { Ud. Instal } \\
25 / 44\end{array}$ & $\begin{array}{l}\text { C/ Perez Galdós esquina } \\
\text { con c/ Suárez Guerra }\end{array}$ & Ecléctico & 1923 \\
\hline 26 & S/C de Tenerife & $\begin{array}{l}\text { Ud. Instal } \\
25 / 51\end{array}$ & $\begin{array}{c}\text { Rambla } 11 \text { de Febrero, } \\
\text { prolongación de calle } 25 \\
\text { de Julio y Numancia }\end{array}$ & Ecléctico & 1923 \\
\hline 27 & S/C de Tenerife & $\begin{array}{l}\text { Ud. Instal } \\
28 / 15\end{array}$ & Calle $1^{a}$, Barrio del Perú & Ecléctico & 1924 \\
\hline 28 & $\mathrm{~S} / \mathrm{C}$ de Tenerife & $\begin{array}{l}\text { Ud. Instal } \\
23 / 25\end{array}$ & C/ General Antequera & Ecléctico & 1924 \\
\hline 29 & $\mathrm{~S} / \mathrm{C}$ de Tenerife & $\begin{array}{l}\text { Ud. Instal } \\
23 / 44\end{array}$ & C/ del Humo n. ${ }^{\circ} 4$ & Ecléctico & 1924 \\
\hline 30 & S/C de Tenerife & $\begin{array}{l}\text { Ud. Instal } \\
23 / 49\end{array}$ & C/ Alfonso XIII n. ${ }^{\circ} 12$ & Ecléctico & 1924 \\
\hline 31 & $\mathrm{~S} / \mathrm{C}$ de Tenerife & $\begin{array}{l}\text { Ud. Instal } \\
24 / 37\end{array}$ & $\mathrm{C} / \mathrm{de}$ los Molinos & Ecléctico & 1924 \\
\hline 32 & S/C de Tenerife & $\begin{array}{l}\text { Ud. Instal } \\
28 / 31\end{array}$ & $\begin{array}{c}\text { C/ San Sebastián detrás } \\
\text { de la Ermita de San } \\
\text { Sebastián }\end{array}$ & Ecléctico & 1924 \\
\hline 33 & $\mathrm{~S} / \mathrm{C}$ de Tenerife & $\begin{array}{l}\text { Ud. Instal } \\
28 / 42\end{array}$ & Rambla de Pulido n. ${ }^{\circ} 50$ & Ecléctico & 1924 \\
\hline 34 & S/C de Tenerife & $\begin{array}{l}\text { Ud. Instal } \\
28 / 44\end{array}$ & Rambla 11 de Febrero & Ecléctico & 1924 \\
\hline 35 & S/C de Tenerife & $\begin{array}{l}\text { Ud. Instal } \\
47 / 87\end{array}$ & C/ Alfonso XIII & Ecléctico & 1924 \\
\hline 36 & $\mathrm{~S} / \mathrm{C}$ de Tenerife & $\begin{array}{l}\text { Ud. Instal } \\
47 / 103\end{array}$ & C/ del Humo n. ${ }^{\circ} 4$ & Ecléctico & 1924 \\
\hline 37 & S/C de Tenerife & $\begin{array}{c}\text { Ud. Instal } \\
47 / 109\end{array}$ & C/ de los Molinos & Ecléctico & 1924 \\
\hline 38 & $\mathrm{~S} / \mathrm{C}$ de Tenerife & $\begin{array}{l}\text { Ud. Instal } \\
47 / 149\end{array}$ & C/ San Sebastián & Ecléctico & 1924 \\
\hline 39 & S/C de Tenerife & $\begin{array}{l}\text { Ud. Instal } \\
27 / 88\end{array}$ & $\begin{array}{c}\text { C/ de Callao de Lima } \\
\text { n. }^{\circ} 33\end{array}$ & Ecléctico & 1925 \\
\hline 40 & La Laguna & $\begin{array}{l}\text { Ud. Instal } \\
605 / 24\end{array}$ & C/ de Belén & Ecléctico & 1925 \\
\hline 41 & $\mathrm{~S} / \mathrm{C}$ de Tenerife & $\begin{array}{l}\text { Ud. Instal } \\
21 / 13\end{array}$ & Rambla de Pulido & Ecléctico & 1925 \\
\hline 42 & S/C de Tenerife & $\begin{array}{l}\text { Ud. Instal } \\
22 / 2\end{array}$ & C/ San Francisco & Ecléctico & 1925 \\
\hline 43 & S/C de Tenerife & $\begin{array}{l}\text { Ud. Instal } \\
22 / 13\end{array}$ & $\begin{array}{c}\text { C/ General Pérez de } \\
\text { Rosas }\end{array}$ & Ecléctico & 1925 \\
\hline 44 & $\mathrm{~S} / \mathrm{C}$ de Tenerife & $\begin{array}{l}\text { Ud. Instal } \\
22 / 31\end{array}$ & $\begin{array}{c}\text { C/ Depósito de Aguas. } \\
\text { Barrio del Perú }\end{array}$ & Ecléctico & 1925 \\
\hline 45 & S/C de Tenerife & $\begin{array}{l}\text { Ud. Instal } \\
22 / 34\end{array}$ & Plaza de la Iglesia . $^{\circ} 15$ & Ecléctico & 1925 \\
\hline 46 & $\mathrm{~S} / \mathrm{C}$ de Tenerife & $\begin{array}{l}\text { Ud. Instal } \\
22 / 37\end{array}$ & $\begin{array}{l}\mathrm{C} / \mathrm{n}^{\circ} 1 \text { Barrio de } \\
\text { Salamanca }\end{array}$ & Ecléctico & 1925 \\
\hline
\end{tabular}


Los remates de cubierta o de composición en los edificios canarios: 1896-1931

\begin{tabular}{|c|c|c|c|c|c|}
\hline 47 & $\mathrm{~S} / \mathrm{C}$ de Tenerife & $\begin{array}{l}\text { Ud. Instal } \\
26 / 121\end{array}$ & Rambla XI de Febrero & Ecléctico & 1925 \\
\hline 48 & $\mathrm{~S} / \mathrm{C}$ de Tenerife & $\begin{array}{l}\text { Ud. Instal } \\
27 / 70\end{array}$ & $\begin{array}{c}\text { C/ San Vicente Ferrer } \\
\text { n. }{ }^{\circ} 17\end{array}$ & Ecléctico & 1925 \\
\hline 49 & $\mathrm{~S} / \mathrm{C}$ de Tenerife & $\begin{array}{l}\text { Ud. Instal } \\
27 / 72\end{array}$ & C/ Valentín Saenz n. ${ }^{\circ} 6$ & Ecléctico & 1925 \\
\hline 50 & S/C de Tenerife & $\begin{array}{l}\text { Ud. Instal } \\
76 / 86\end{array}$ & $\begin{array}{l}\text { C/ Suárez Guerra n. }{ }^{\circ} 4 \\
\text { esquina con c/ Castillo } \\
\text { n. }{ }^{\circ} 59\end{array}$ & Ecléctico & 1926 \\
\hline 51 & $\mathrm{~S} / \mathrm{C}$ de Tenerife & $\begin{array}{l}\text { Ud. Instal } \\
545 / 4\end{array}$ & $\begin{array}{l}\text { C/ Santa Rosalía esquina } \\
\text { con prolongación de c/ } \\
\text { Callao de Lima }\end{array}$ & Ecléctico & 1926 \\
\hline 52 & $\mathrm{~S} / \mathrm{C}$ de Tenerife & $\begin{array}{l}\text { Ud. Instal } \\
75 / 23\end{array}$ & $\begin{array}{l}\text { C/ Tinguaro frente a la } \\
\text { Cruz del Señor }\end{array}$ & Ecléctico & 1926 \\
\hline 53 & $\mathrm{~S} / \mathrm{C}$ de Tenerife & $\begin{array}{l}\text { Ud. Instal } \\
76 / 57\end{array}$ & C/ San Miguel n. ${ }^{\circ} 35$ & Ecléctico & 1926 \\
\hline 54 & $\mathrm{~S} / \mathrm{C}$ de Tenerife & $\begin{array}{l}\text { Ud. Instal } \\
76 / 67\end{array}$ & $\begin{array}{c}\text { C/ Pescadores y Callejón } \\
\text { de las Monjas }\end{array}$ & Ecléctico & 1926 \\
\hline 55 & $\mathrm{~S} / \mathrm{C}$ de Tenerife & $\begin{array}{l}\text { Ud. Instal } \\
76 / 69\end{array}$ & Barrio del Perú & Ecléctico & 1926 \\
\hline 56 & $\mathrm{~S} / \mathrm{C}$ de Tenerife & $\begin{array}{l}\text { Ud. Instal } \\
77 / 150\end{array}$ & c/ San Antonio n. ${ }^{\circ} 8$ & Ecléctico & 1926 \\
\hline 57 & $\mathrm{~S} / \mathrm{C}$ de Tenerife & $\begin{array}{l}\text { Ud. Instal } \\
76 / 98\end{array}$ & C/ Alfonso XIII n. ${ }^{\circ} 26$ & Ecléctico & 1926 \\
\hline 58 & $\mathrm{~S} / \mathrm{C}$ de Tenerife & $\begin{array}{l}\text { Ud. Instal } \\
\quad 92 / 9\end{array}$ & $\begin{array}{l}\text { C/ Mendez Nuñez } \\
\text { esquina con c/ Santa } \\
\text { Rosalía y Ferrer }\end{array}$ & Ecléctico & 1927 \\
\hline 59 & S/C de Tenerife & $\begin{array}{l}\text { Ud. Instal } \\
94 / 105\end{array}$ & $\begin{array}{l}\text { C/ Santiago esquina al } \\
\text { Pasaje de Pisaca }\end{array}$ & Ecléctico & 1927 \\
\hline 60 & $\mathrm{~S} / \mathrm{C}$ de Tenerife & $\begin{array}{l}\text { Ud. Instal } \\
94 / 113\end{array}$ & C/ Callao de Lima n. ${ }^{\circ} 54$ & Ecléctico & 1927 \\
\hline 61 & S/C de Tenerife & $\begin{array}{l}\text { Ud. Instal } \\
94 / 130\end{array}$ & C/ Suárez Guerra n. ${ }^{\circ} 44$ & Ecléctico & 1927 \\
\hline 62 & $\mathrm{~S} / \mathrm{C}$ de Tenerife & $\begin{array}{l}\text { Ud. Instal } \\
95 / 151\end{array}$ & $\begin{array}{l}\text { C/ de Miraflores n. }{ }^{\circ} 1 \text { y } \\
\text { c/ Dominguez Alfonso } \\
\text { n. } 36\end{array}$ & Ecléctico & 1927 \\
\hline 63 & $\mathrm{~S} / \mathrm{C}$ de Tenerife & $\begin{array}{l}\text { Ud. Instal } \\
389 / 19\end{array}$ & $\begin{array}{c}\text { C/ de Pérez Galdós n. } \\
9 \text { y } 11\end{array}$ & Ecléctico & 1927 \\
\hline
\end{tabular}

En 1922 se han detectado dos edificios con remates de cubierta de Pisaca, el número 21 y 22, y ya denota un uso importante de este ornato. En el n. ${ }^{\circ} 21$, no solamente lo encontramos en los dinteles y en la cubierta, sino también sobre el antepecho de los balcones. Aparecen diseños variados, desde los más pequeños hasta auténticas urnas de tamaño considerable. Darias los nombra, referido a uno de estos remates de Pisaca como copas de boca ancha o con tapa (DARIAS, 1985: 389). En el caso del dintel, encontramos la disposición tripartita que indica Darias sobre los tres elementos: laterales gemelos y central más rico (DARIAS, 1985: 398), los laterales son nuestros remates, pero en este caso no son esferas sobre hojas de 
acanto que indica, sino copas cerradas de tamaño moderado; el central se trata de una disposición floral en diadema. En el edificio n. ${ }^{\circ} 22$, un singular diseño de forma ovoide con malla decora la cubierta.

En 1923, Pisaca utiliza el remate de cubierta en 4 edificios localizados, los números 23, 24, 25 y 26. La definición de los detalles y minuciosidad de las formas es creciente y notable ayudada por el uso inteligente del color en los planos. En los dos primeros edificios se tiende a la esbeltez de los remates, algunos de ellos pudiéndose clasificar como pináculos, lo cual aporta verticalidad al edificio, pero debe apreciarse que la escala importa, no solo la esbeltez, pues en el edificio n. ${ }^{\circ}$ 23 la pequeña escala de los mismos no consigue el mismo efecto que el número 24, de mayor tamaño. Los dos edificios siguientes no son tan esbeltos pero poseen gran calidad como ocurre con el remate que mostramos en la figura 7 izquierda. En el edificio número 25 se toma como base el sencillo diseño en esfera de la figura 2 izquierda y se le aportan complementos que lo mejoran sobradamente como las bandas perimetrales con hojas en curva sobre elegantes apoyos de tres patas. Los diseños no se repiten y las ubicaciones se amplían: encontramos remates en otras zonas no nombradas como en los laterales del alfeizar (edificio n. ${ }^{\circ} 23$ ), o en la parte central de los balcones sobre el antepecho y frente a la ventana (edificio n. $\left.{ }^{\circ} 26\right)$. Se observan la educación modernista de Pisaca en algunos detalles, como los tragaluces de los edificios n. ${ }^{\circ} 23$ y 26 y el golpe de látigo que indica Darias en la rejería de este último (DARIAS, 1985: 384).

En 1924 el número de edificios con remates de cubierta de Pisaca es importante, pues cuenta con un total de 12, (del n. ${ }^{\circ} 27$ al n. ${ }^{\circ} 38$ ). Si el edificio es sencillo y de una planta la decoración es moderada, como ocurre con el n. ${ }^{\circ}$ 27 en el que utiliza el diseño sencillo en esfera de la figura 2 izquierda en los dinteles, y lo mejora en la cubierta al disponerlo sobre capullo de acanto que se refiere Darias cuando comenta los remates de los huecos de Pisaca (Darias, 1985: 398). En el edificio n. ${ }^{\circ} 28$ imperan más los jarrones, dejando el remate para el pabellón, con un diseño de hojas similar a una antefija. Continúan los detalles modernistas en los tragaluces y en el antepecho y hasta el dintel se curva al estilo art-nouveau. En los edificios n. ${ }^{\circ} 29$ y 36 de una planta impera la sencillez, con un bonito diseño de remate de cubierta en capullo similar a la figura 2 derecha. La esfera se decora en el edificio n. ${ }^{\circ} 30$ y también su pedestal, a diferencia del n. ${ }^{\circ} 31,32,37$ y 38 de una planta que se presenta sencilla. En el número 33 Pisaca innova mediante un diseño de remate formado por una pirámide sobre acantos ubicados en los antepechos de cubierta y balcón, y en edificio n. ${ }^{\circ} 34$ en los laterales del alfeizar, antepecho de balcón y dintel, con un moderado diseño de capullos invertidos en un edificio impresionantemente decorado. Repite su habitual esfera decorada encintada sobre pedestal decorado con roleos en el edificio n. ${ }^{\circ} 35$, sobre el antepecho de cubierta.

En 1925 Pisaca vuelve a sorprender con 11 edificios con remates de cubierta localizados (del n. ${ }^{\circ} 39$ al n. ${ }^{\circ} 49$ ). En ellos vuelve a combinar sus acostumbrados diseños en esfera o semiesfera, encintadas o con motivos vegetales, con esbelteces que en algunos casos adquieren tintes de pináculos. En la cubierta del edificio n. ${ }^{\circ}$ 40 esboza un diseño muy común que se distingue por su forma peculiar: un cubo de lados con resalte sobre pedestal y culminado por una pequeña esfera, que no duda en modificarlo en el edificio n. ${ }^{\circ} 47$ aportándole decoración geométrica en sus caras y orgánica en su parte superior. En el n. ${ }^{\circ} 44$, dispone un remate sencillo en esfera sobre el antepecho del balcón, con forma de peón de ajedrez al que 
se refiere Darias como menos frecuente (Darias, 1985: 389). Las ubicaciones se concentran en la cubierta, dinteles y antepecho de balcón para los más pequeños.

En este último año indicado, a pesar de contar con un edificio menos, la ornamentación es mayor porque solamente cuenta con dos edificios de una planta y como hemos indicado, a mayor número de plantas Pisaca suele incrementar el ornato en ellos. En el año siguiente de 1926, se reduce el número de edificios con remate de cubierta a ocho. Son los edificios números 50 al 57, en los que se apuesta por la combinación de pináculos con remates en el antepecho de cubierta, se trata de su acostumbrado diseño en peón de ajedrez, especialmente en los balcones, y las modalidades de diseño en esfera geométrica o vegetal. La copa cerrada reaparece con cierta majestuosidad en su diseño, además de la combinación de su típica forma cuadrangular con otro remate tronco-piramidal entre base de roleos y esfera superior. Finalmente, en el último edificio n. ${ }^{\circ} 57$ de este año, se apuesta por aumentar la esbeltez del remate de cubierta para competir con los pináculos en un diseño de esfera sobre capullo de acanto muy estilizado.

Para el año 1927, mostramos los últimos seis edificios localizados de Pisaca con remates de cubierta. Los diseños elegidos se concentran básicamente en sus formas habituales, como su típico peón de ajedrez, copa con tapa o variantes de sus formas en esfera, pero también vuelve a innovar con diseños de formas ovoides o rodeos utilizados como remates. En este último año, Pisaca usa moderadamente sus recursos ornamentales por tratarse la mayor parte de los edificios de solo dos plantas.
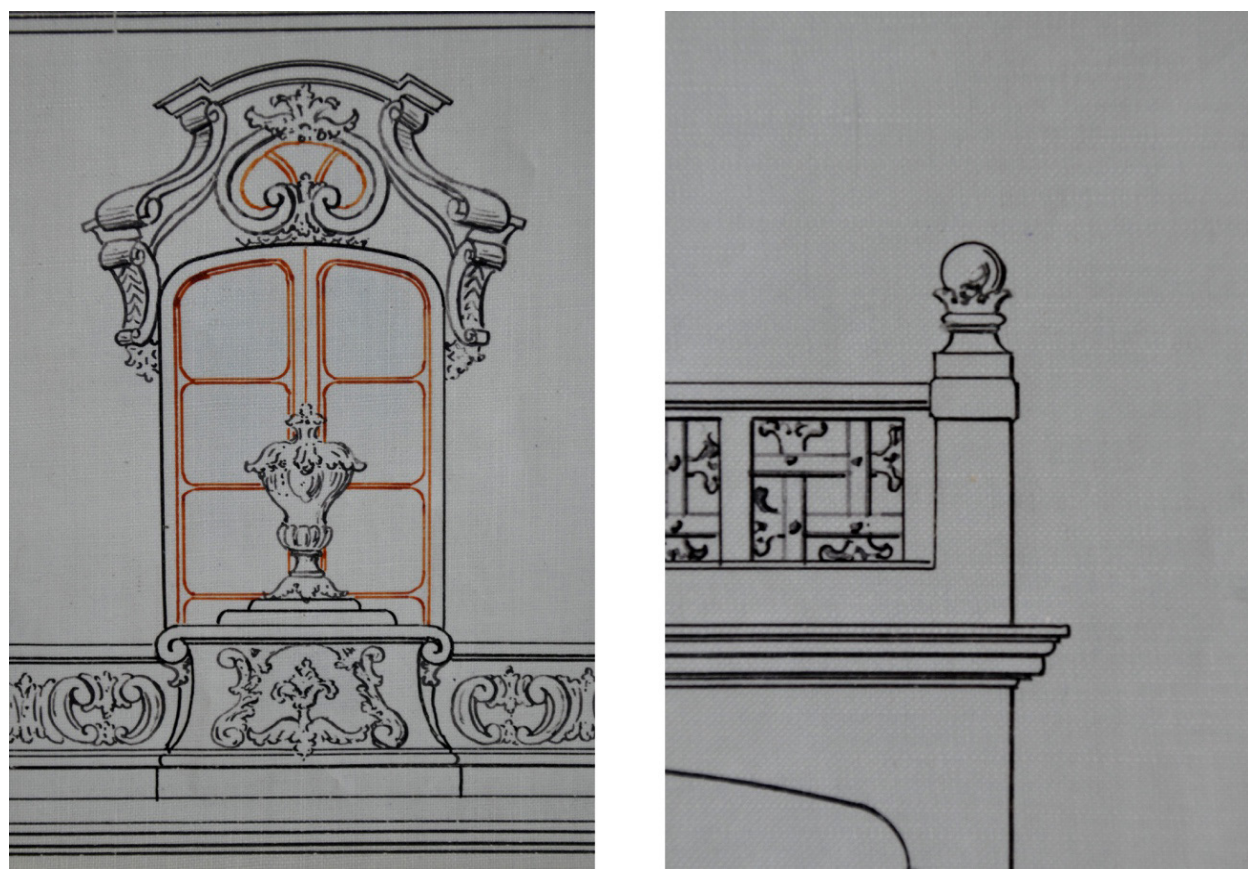

Figura 7. Remate de cubierta en el balcón . Ornato público. Ud Instal 25-51.Archivo Mpal S/C Tfe. Arqto. Domingo Pisaca (izquierda). Remate de cubierta Unid.Instal 30-18. Archivo Mpal. S/C Tfe. Arqto. Antonio Pintor (derecha). Fotos: José Antonio Sabina González. 


\subsection{Antonio Pintor y Ocete}

Finalmente tratamos a Antonio Pintor, que también ha utilizado el remate de cubierta en sus edificios. Este arquitecto nació en Granada, como nos indica Darias, donde comenzó sus estudios para posteriormente continuarlos en Madrid y Barcelona. Pintor llegó a Tenerife a través de una plaza de arquitecto municipal que presentó el ayuntamiento, participando en este cargo en los trabajos del ensanche de Santa Cruz, trazando su crecimiento. Darias destaca también que Pintor demostró ser muy generoso (DARIAS, 1985: 175-179).

TABLA 8

Edificios de Antonio Pintor que han incorporado el remate de cubierta

\begin{tabular}{|c|c|c|c|c|c|}
\hline $\begin{array}{l}\mathrm{N}^{\mathrm{o}} \\
\text { orden }\end{array}$ & $\begin{array}{c}\text { Archivo } \\
\text { Municipal }\end{array}$ & Expediente & Dirección & $\begin{array}{l}\text { Tipología } \\
\text { Lenguaje }\end{array}$ & $\begin{array}{c}\text { Año } \\
\text { Licencia }\end{array}$ \\
\hline 64 & $\begin{array}{l}\text { S/C de } \\
\text { Tenerife }\end{array}$ & Ud. Instal 79/69 & $\begin{array}{l}\text { C/ Santo Domingo } \\
\text { esquina con c/ Cruz } \\
\text { Verde }\end{array}$ & Ecléctico & 1909 \\
\hline 65 & $\begin{array}{l}\text { S/C de } \\
\text { Tenerife }\end{array}$ & Ud. Instal 78/48 & $\begin{array}{c}\text { C/ Valentín Sanz n. }{ }^{\circ} \\
13 \text { y } 15\end{array}$ & Ecléctico & 1910 \\
\hline 66 & $\begin{array}{l}\text { S/C de } \\
\text { Tenerife }\end{array}$ & Ud. Instal 15/41 & Barrio de Los Llanos & Ecléctico & 1910 \\
\hline 67 & $\begin{array}{l}\text { S/C de } \\
\text { Tenerife }\end{array}$ & Ud. Instal 07/25 & $\begin{array}{l}\mathrm{C} / \text { Mendez }^{\circ} .^{\circ} \\
1 \text { esquina con c/ } \\
\text { Robayna }\end{array}$ & Ecléctico & 1911 \\
\hline 68 & $\begin{array}{l}\text { S/C de } \\
\text { Tenerife }\end{array}$ & Ud. Instal 18/41 & $\begin{array}{l}\text { C/ San Francisco Javier } \\
\text { n. }{ }^{\circ} 16\end{array}$ & Modernista & 1912 \\
\hline 69 & $\begin{array}{l}\text { S/C de } \\
\text { Tenerife }\end{array}$ & Ud. Instal 20/19 & $\begin{array}{c}\text { Plaza de La } \\
\text { Constructora n. }{ }^{\circ 2}\end{array}$ & Ecléctico & 1912 \\
\hline 70 & La Laguna & $\begin{array}{l}\text { Ud. Instal } \\
601 / 44\end{array}$ & $\begin{array}{l}\text { C/ Núñez de La Peña } \\
\text { esquina con c/ Obispo } \\
\text { Rey Redondo }\end{array}$ & Ecléctico & 1913 \\
\hline 71 & $\begin{array}{l}\text { S/C de } \\
\text { Tenerife }\end{array}$ & Ud. Instal 32/1 & $\begin{array}{c}\text { Km } 4 \text { de la carretera de } \\
\text { Santa Cruz de Tenerife } \\
\text { a La Orotava }\end{array}$ & Ecléctico & 1913 \\
\hline 72 & $\begin{array}{l}\mathrm{S} / \mathrm{C} \text { de } \\
\text { Tenerife }\end{array}$ & Ud. Instal 32/14 & C/ Valentín Sanz n. ${ }^{\circ} 3$ & Ecléctico & 1913 \\
\hline 73 & $\begin{array}{l}\text { S/C de } \\
\text { Tenerife }\end{array}$ & Ud. Instal 32/21 & C/ Los Campos n. ${ }^{\circ} 22$ & Ecléctico & 1913 \\
\hline 74 & La Laguna & $\begin{array}{l}\text { Ud. Instal } \\
601 / 59\end{array}$ & C/ Nava y Grimón & Ecléctico & 1914 \\
\hline 75 & $\begin{array}{l}\text { S/C de } \\
\text { Tenerife }\end{array}$ & Ud. Instal 32/52 & C/ Pérez Galdós n. ${ }^{\circ} 6$ & Ecléctico & 1915 \\
\hline 76 & $\begin{array}{l}\text { S/C de } \\
\text { Tenerife }\end{array}$ & Ud. Instal 13/6 & $\begin{array}{l}\text { Prolongación c/ } \\
\text { Benavides }\end{array}$ & Ecléctico & 1916 \\
\hline
\end{tabular}


Los remates de cubierta o de composición en los edificios canarios: 1896-1931

\begin{tabular}{|c|c|c|c|c|c|}
\hline 77 & $\begin{array}{l}\text { S/C de } \\
\text { Tenerife }\end{array}$ & Ud. Instal 13/13 & $\begin{array}{c}\text { Calles Dr Allart, San } \\
\text { Pedro Alcántara y } \\
\text { Clavel }\end{array}$ & Ecléctico & 1916 \\
\hline 78 & $\begin{array}{l}\text { S/C de } \\
\text { Tenerife }\end{array}$ & Ud. Instal 13/42 & C/ Dr. Comenge n. ${ }^{\circ} 10$ & Ecléctico & 1917 \\
\hline 79 & $\begin{array}{l}\text { S/C de } \\
\text { Tenerife }\end{array}$ & Ud. Instal 17/47 & $\begin{array}{c}\text { C/ Rambla de Pulido } \\
\text { n. }{ }^{\circ} 25\end{array}$ & Ecléctico & 1918 \\
\hline 80 & $\begin{array}{l}\text { S/C de } \\
\text { Tenerife }\end{array}$ & Ud. Instal 14/49 & $\begin{array}{l}\text { C/ Rambla de Pulido } \\
\text { n. }{ }^{\circ} 56\end{array}$ & Ecléctico & 1919 \\
\hline 81 & $\begin{array}{l}\text { S/C de } \\
\text { Tenerife }\end{array}$ & Ud. Instal 14/53 & $\begin{array}{l}\text { C/ Teobaldo Power } \\
\text { n. }{ }^{\circ} 25\end{array}$ & Ecléctico & 1919 \\
\hline 82 & $\begin{array}{l}\text { S/C de } \\
\text { Tenerife }\end{array}$ & Ud. Instal 14/15 & C/ San Lucas & Ecléctico & 1920 \\
\hline 83 & $\begin{array}{l}\text { S/C de } \\
\text { Tenerife }\end{array}$ & Ud. Instal 14/26 & $\begin{array}{c}\text { C/ Eduardo Cobián } \\
\text { n. }^{\circ} 27\end{array}$ & Ecléctico & 1920 \\
\hline 84 & $\begin{array}{l}\text { S/C de } \\
\text { Tenerife }\end{array}$ & Ud. Instal 23/60 & C/ Dr. Comenge n. ${ }^{\circ} 80$ & Ecléctico & 1921 \\
\hline 85 & $\begin{array}{l}\text { S/C de } \\
\text { Tenerife }\end{array}$ & Ud. Instal 44/54 & C/ 25 de Julio n. ${ }^{\circ} 12$ & Ecléctico & 1921 \\
\hline 86 & $\begin{array}{l}\text { S/C de } \\
\text { Tenerife }\end{array}$ & Ud. Instal 41/20 & $\begin{array}{l}\text { Rambla XI de Febrero } \\
\text { n. }{ }^{\circ} 12\end{array}$ & Ecléctico & 1922 \\
\hline 87 & $\begin{array}{l}\text { S/C de } \\
\text { Tenerife }\end{array}$ & Ud. Instal 41/57 & C/ Noria Alta & Ecléctico & 1922 \\
\hline 88 & $\begin{array}{l}\text { S/C de } \\
\text { Tenerife }\end{array}$ & Ud. Instal 41/63 & $\begin{array}{l}\text { C/ Jesús y María y c/ } \\
\text { de Viera y Clavijo }\end{array}$ & Ecléctico & 1922 \\
\hline 89 & $\begin{array}{l}\text { S/C de } \\
\text { Tenerife }\end{array}$ & Ud. Instal 41/49 & $\begin{array}{l}\text { C/ particular de } \\
\text { Gaspar Fernández }\end{array}$ & Ecléctico & 1922 \\
\hline 90 & $\begin{array}{l}\text { S/C de } \\
\text { Tenerife }\end{array}$ & Ud. Instal 41/28 & $\begin{array}{c}\text { Carretera de San } \\
\text { Andrés }\end{array}$ & Ecléctico & 1922 \\
\hline 91 & $\begin{array}{l}\text { S/C de } \\
\text { Tenerife }\end{array}$ & Ud. Instal 48/32 & $\begin{array}{c}\text { Rambla General Franco } \\
\text { n. }{ }^{\circ} 61 \text { esquina con c/ } \\
\text { del General Ramos } \\
\text { Serrano n. } .^{\circ} 2 \\
\end{array}$ & Ecléctico & 1922 \\
\hline 92 & $\begin{array}{l}\text { S/C de } \\
\text { Tenerife }\end{array}$ & Ud. Instal 24/48 & $\mathrm{C} /$ de la Marina & Ecléctico & 1923 \\
\hline 93 & $\begin{array}{l}\text { S/C de } \\
\text { Tenerife }\end{array}$ & Ud. Instal 25/43 & $\begin{array}{c}\text { C/ Ferrer n. } .^{\circ} 14 \text { y } 15, \\
\text { c/ Santa Rosa de Lima } \\
\text { n. }{ }^{\circ} 13 \text { y c/ Francisco } \\
\text { Javier }\end{array}$ & Ecléctico & 1923 \\
\hline 94 & $\begin{array}{l}\text { S/C de } \\
\text { Tenerife }\end{array}$ & Ud. Instal 25/48 & $\begin{array}{c}\text { Avenida de Las } \\
\text { Asuncionistas }\end{array}$ & Ecléctico & 1923 \\
\hline 95 & $\begin{array}{l}\text { S/C de } \\
\text { Tenerife }\end{array}$ & Ud. Instal 21/17 & $\begin{array}{c}\text { C/ Pérez Galdós } \\
\text { esquina con c/ Suarez } \\
\text { Guerra }\end{array}$ & Ecléctico & 1923 \\
\hline 96 & $\begin{array}{l}\text { S/C de } \\
\text { Tenerife }\end{array}$ & Ud. Instal 30/05 & $\begin{array}{l}\text { C/ } 25 \text { de Julio esquina } \\
\text { con c/ Wolfson }\end{array}$ & Ecléctico & 1923 \\
\hline 97 & $\begin{array}{l}\text { S/C de } \\
\text { Tenerife }\end{array}$ & Ud. Instal 30/18 & C/ Numancia & Ecléctico & 1923 \\
\hline
\end{tabular}


José Antonio Sabina González

\begin{tabular}{|c|c|c|c|c|c|}
\hline 98 & $\begin{array}{l}\text { S/C de } \\
\text { Tenerife }\end{array}$ & Ud. Instal 30/36 & C/ Dr. Costa & Ecléctico & 1923 \\
\hline 99 & $\begin{array}{l}\text { S/C de } \\
\text { Tenerife }\end{array}$ & Ud. Instal 28/37 & $\begin{array}{l}\text { C/ Méndez Núñez } \\
\text { n. }{ }^{\circ} 46\end{array}$ & Ecléctico & 1924 \\
\hline 100 & $\begin{array}{l}\text { S/C de } \\
\text { Tenerife }\end{array}$ & Ud. Instal 28/47 & $\begin{array}{l}\text { Plaza de la Iglesia n. }^{\circ} \\
15\end{array}$ & Ecléctico & 1924 \\
\hline 101 & $\begin{array}{l}\text { S/C de } \\
\text { Tenerife }\end{array}$ & Ud. Instal 39/2 & C/ Robayna n. ${ }^{\circ} 27$ & Ecléctico & 1924 \\
\hline 102 & $\begin{array}{l}\text { S/C de } \\
\text { Tenerife }\end{array}$ & $\begin{array}{l}\text { Ud. Instal } \\
47 / 137\end{array}$ & C/ Viera y Clavijo & Ecléctico & 1924 \\
\hline 103 & $\begin{array}{l}\text { S/C de } \\
\text { Tenerife }\end{array}$ & Ud. Instal 23/35 & $\begin{array}{l}\text { Carretera de La Laguna } \\
\text { entre los kms. } 1 \text { y } 2\end{array}$ & Ecléctico & 1924 \\
\hline 104 & $\begin{array}{l}\text { S/C de } \\
\text { Tenerife }\end{array}$ & Ud. Instal 24/8 & Camino de los Coches & Ecléctico & 1924 \\
\hline 105 & $\begin{array}{l}\text { S/C de } \\
\text { Tenerife }\end{array}$ & Ud. Instal 24/28 & $\begin{array}{c}\text { C/ Imeldo Serís n. }{ }^{\circ} 17 \\
\text { y } 19\end{array}$ & Ecléctico & 1924 \\
\hline 106 & $\begin{array}{l}\text { S/C de } \\
\text { Tenerife }\end{array}$ & Ud. Instal 28/2 & $\begin{array}{l}\text { C/ Eduardo Cobián y } \\
\text { Avenida de Cuba }\end{array}$ & Ecléctico & 1924 \\
\hline 107 & $\begin{array}{l}\text { S/C de } \\
\text { Tenerife }\end{array}$ & Ud. Instal 28/8 & $\begin{array}{l}\text { C/ Particular en el } \\
\text { Puente de Zurita }\end{array}$ & Ecléctico & 1924 \\
\hline 108 & $\begin{array}{l}\text { S/C de } \\
\text { Tenerife }\end{array}$ & Ud. Instal 28/13 & C/ de la Gomera & Ecléctico & 1924 \\
\hline 109 & $\begin{array}{l}\text { S/C de } \\
\text { Tenerife }\end{array}$ & Ud. Instal 28/24 & C/ de la Gomera & Ecléctico & 1924 \\
\hline 110 & $\begin{array}{l}\text { S/C de } \\
\text { Tenerife }\end{array}$ & Ud. Instal 28/27 & $\begin{array}{c}\text { C/ Teobaldo Power } \\
\text { n. } 7\end{array}$ & Ecléctico & 1924 \\
\hline 111 & $\begin{array}{l}\text { S/C de } \\
\text { Tenerife }\end{array}$ & Ud. Instal 23/23 & C/ Viera y Clavijo & Ecléctico & 1924 \\
\hline 112 & $\begin{array}{l}\text { S/C de } \\
\text { Tenerife }\end{array}$ & Ud. Instal 23/27 & $\begin{array}{c}\text { C/ Rambla del Gral. } \\
\text { Franco n.19 esquina } \\
\text { con c/ Gral. Trujillo } \\
\text { n. }{ }^{\circ} 1\end{array}$ & Ecléctico & 1924 \\
\hline 113 & $\begin{array}{l}\text { S/C de } \\
\text { Tenerife }\end{array}$ & Ud. Instal 23/30 & $\begin{array}{c}\text { C/ Suarez Guerra n. }{ }^{\circ} \\
28 \\
\end{array}$ & Ecléctico & 1924 \\
\hline 114 & $\begin{array}{l}\text { S/C de } \\
\text { Tenerife }\end{array}$ & Ud. Instal 22/23 & C/ de la Gomera & Ecléctico & 1925 \\
\hline 115 & $\begin{array}{l}\text { S/C de } \\
\text { Tenerife }\end{array}$ & Ud. Instal 22/29 & $\begin{array}{l}\text { Plaza de la Isla de la } \\
\text { Madera n. } .^{\circ} 12\end{array}$ & Ecléctico & 1925 \\
\hline 116 & $\begin{array}{l}\text { S/C de } \\
\text { Tenerife }\end{array}$ & Ud. Instal 26/95 & $\begin{array}{c}\text { C/ de Noria Alta } \\
\text { esquina a la c/ de } \\
\text { Benavidez }\end{array}$ & Ecléctico & 1925 \\
\hline 117 & $\begin{array}{l}\text { S/C de } \\
\text { Tenerife }\end{array}$ & $\begin{array}{l}\text { Ud. Instal } \\
26 / 111\end{array}$ & $\begin{array}{l}\text { Rambla XI de Febrero } \\
\text { esquina con c/ Lucas } \\
\text { Fernández Navarrro }\end{array}$ & Ecléctico & 1925 \\
\hline 118 & $\begin{array}{l}\text { S/C de } \\
\text { Tenerife }\end{array}$ & $\begin{array}{c}\text { Ud. Instal } \\
26 / 112\end{array}$ & C/ de Miraflores n. ${ }^{\circ} 24$ & Ecléctico & 1925 \\
\hline 119 & $\begin{array}{l}\text { S/C de } \\
\text { Tenerife }\end{array}$ & $\begin{array}{l}\text { Ud. Instal } \\
26 / 136\end{array}$ & C/ Costa y Grijalba & Ecléctico & 1925 \\
\hline
\end{tabular}


Los remates de cubierta o de composición en los edificios canarios: 1896-1931

\begin{tabular}{|c|c|c|c|c|c|}
\hline 120 & $\begin{array}{l}\text { S/C de } \\
\text { Tenerife }\end{array}$ & $\begin{array}{l}\text { Ud. Instal } \\
26 / 138\end{array}$ & $\begin{array}{l}\text { C/ de José Suarez } \\
\text { Guerra n. }{ }^{\circ} 23\end{array}$ & Ecléctico & 1925 \\
\hline 121 & $\begin{array}{l}\text { S/C de } \\
\text { Tenerife }\end{array}$ & $\begin{array}{l}\text { Ud. Instal } \\
26 / 140\end{array}$ & $\begin{array}{c}\text { C/ de Salamanca } \\
\text { esquina con c/ primera } \\
\text { de obreros }\end{array}$ & Ecléctico & 1925 \\
\hline 122 & $\begin{array}{l}\text { S/C de } \\
\text { Tenerife }\end{array}$ & Ud. Instal 27/57 & $\begin{array}{c}\text { C/ Valentín Sanz } \\
\text { n. } 8 \text { esquina con c/ } \\
\text { Bethencourt Alfonso }\end{array}$ & Ecléctico & 1925 \\
\hline 123 & $\begin{array}{l}\text { S/C de } \\
\text { Tenerife }\end{array}$ & Ud. Instal 27/60 & $\begin{array}{c}\text { C/ Suarez Guerra } \\
\text { esquina con c/ Alfonso } \\
\text { XIII }\end{array}$ & Ecléctico & 1925 \\
\hline 124 & $\begin{array}{l}\text { S/C de } \\
\text { Tenerife }\end{array}$ & Ud. Instal 27/68 & $\begin{array}{c}\text { C/ Puerta Canseco } \\
\text { n. } 59\end{array}$ & Ecléctico & 1925 \\
\hline 125 & $\begin{array}{l}\text { S/C de } \\
\text { Tenerife }\end{array}$ & Ud. Instal 27/71 & C/ de Duggi & Ecléctico & 1925 \\
\hline 126 & $\begin{array}{l}\text { S/C de } \\
\text { Tenerife }\end{array}$ & Ud. Instal 27/83 & $\begin{array}{l}\text { C/ de Salamanca } \\
\text { esquina con c/ de La } \\
\text { Gomera }\end{array}$ & Ecléctico & 1925 \\
\hline 127 & $\begin{array}{l}\text { S/C de } \\
\text { Tenerife }\end{array}$ & $\begin{array}{l}\text { Ud. Instal } \\
77 / 134\end{array}$ & $\begin{array}{l}\text { Avenida del General } \\
\text { Mola n. }{ }^{\circ} 7\end{array}$ & Ecléctico & 1925 \\
\hline 128 & $\begin{array}{l}\text { S/C de } \\
\text { Tenerife }\end{array}$ & $\begin{array}{l}\text { Ud. Instal } \\
76 / 114\end{array}$ & C/ del Fomento n. ${ }^{\circ} 12$ & Ecléctico & 1925 \\
\hline 129 & $\begin{array}{l}\text { S/C de } \\
\text { Tenerife }\end{array}$ & Ud. Instal 75/52 & C/ de Méndez Núñez & Ecléctico & 1926 \\
\hline 130 & $\begin{array}{l}\text { S/C de } \\
\text { Tenerife }\end{array}$ & Ud. Instal 76/69 & Barrio del Perú & Ecléctico & 1926 \\
\hline 131 & $\begin{array}{l}\text { S/C de } \\
\text { Tenerife }\end{array}$ & Ud. Instal 76/74 & $\begin{array}{l}\text { C/ de la Prosperidad y } \\
\text { c/ Isla de la Gomera }\end{array}$ & Ecléctico & 1926 \\
\hline 132 & $\begin{array}{l}\text { S/C de } \\
\text { Tenerife }\end{array}$ & $\begin{array}{l}\text { Ud. Instal } \\
77 / 122\end{array}$ & $\begin{array}{l}\text { Plaza de la Iglesia n. }^{\circ} \\
14 \text { y } 15\end{array}$ & Ecléctico & 1926 \\
\hline 133 & $\begin{array}{l}\text { S/C de } \\
\text { Tenerife }\end{array}$ & $\begin{array}{l}\text { Ud. Instal } \\
77 / 149\end{array}$ & $\begin{array}{l}\text { Paseo de las } \\
\text { Asuncionistas }\end{array}$ & Ecléctico & 1926 \\
\hline 134 & $\begin{array}{l}\text { S/C de } \\
\text { Tenerife }\end{array}$ & $\begin{array}{l}\text { Ud. Instal } \\
77 / 151\end{array}$ & $\begin{array}{c}\text { C/ de Lucas Fernández } \\
\text { Navarro }\end{array}$ & Ecléctico & 1926 \\
\hline 135 & $\begin{array}{l}\text { S/C de } \\
\text { Tenerife }\end{array}$ & $\begin{array}{l}\text { Ud. Instal } \\
77 / 114\end{array}$ & $\begin{array}{l}\text { Rambla XI de Febrero } \\
\text { n. }{ }^{\circ} 83\end{array}$ & Ecléctico & 1926 \\
\hline 136 & $\begin{array}{l}\text { S/C de } \\
\text { Tenerife }\end{array}$ & $\begin{array}{l}\text { Ud. Instal } \\
76 / 103\end{array}$ & $\begin{array}{l}\text { C/ Trasera de } \\
\text { Pescadores }\end{array}$ & Ecléctico & 1926 \\
\hline 137 & $\begin{array}{l}\text { S/C de } \\
\text { Tenerife }\end{array}$ & $\begin{array}{l}\text { Ud. Instal } \\
76 / 112\end{array}$ & $\begin{array}{l}\text { Pasaje de Reyes en el } \\
\text { barrio de Buenavista }\end{array}$ & Ecléctico & 1926 \\
\hline 138 & $\begin{array}{l}\text { S/C de } \\
\text { Tenerife }\end{array}$ & Ud. Instal 76/69 & Barrio del Perú & Ecléctico & 1926 \\
\hline 139 & $\begin{array}{l}\text { S/C de } \\
\text { Tenerife }\end{array}$ & Ud. Instal 75/6 & C/ de Salamanca & Ecléctico & 1926 \\
\hline 140 & $\begin{array}{l}\text { S/C de } \\
\text { Tenerife }\end{array}$ & Ud. Instal 75/22 & $\begin{array}{l}\text { C/ de Fomento y } \\
\text { Rambla de Pulido }\end{array}$ & Ecléctico & 1926 \\
\hline 141 & $\begin{array}{l}\text { S/C de } \\
\text { Tenerife }\end{array}$ & Ud. Instal 75/24 & C/ de la Marina & Ecléctico & 1926 \\
\hline
\end{tabular}


José Antonio Sabina González

\begin{tabular}{|c|c|c|c|c|c|}
\hline 142 & $\begin{array}{l}\text { S/C de } \\
\text { Tenerife }\end{array}$ & Ud. Instal 75/31 & C/ de Salamanca & Ecléctico & 1926 \\
\hline 143 & $\begin{array}{l}\text { S/C de } \\
\text { Tenerife }\end{array}$ & Ud. Instal 75/34 & $\mathrm{C} /$ de Salamanca n. ${ }^{\circ} 3$ & Ecléctico & 1926 \\
\hline 144 & $\begin{array}{l}\text { S/C de } \\
\text { Tenerife }\end{array}$ & Ud. Instal 75/35 & Camino del Manicomio & Ecléctico & 1926 \\
\hline 145 & $\begin{array}{l}\text { S/C de } \\
\text { Tenerife }\end{array}$ & Ud. Instal 75/38 & $\begin{array}{l}\text { C/ de Isla de La } \\
\text { Gomera }\end{array}$ & Ecléctico & 1926 \\
\hline 146 & $\begin{array}{l}\text { S/C de } \\
\text { Tenerife }\end{array}$ & Ud. Instal 92/6 & $\begin{array}{l}\text { C/ de Salamanca n. }{ }^{\circ} \\
28 \text { esquina con c/ de la } \\
\text { Prosperidad n. } .^{\circ} 15\end{array}$ & Ecléctico & 1927 \\
\hline 147 & $\begin{array}{l}\text { S/C de } \\
\text { Tenerife }\end{array}$ & Ud. Instal 92/14 & $\begin{array}{l}\mathrm{C} / \text { de la Igualdad n. } \\
47\end{array}$ & Ecléctico & 1927 \\
\hline 148 & $\begin{array}{l}\text { S/C de } \\
\text { Tenerife }\end{array}$ & Ud. Instal 92/36 & $\begin{array}{c}\text { C/ de Lucas Fernández } \\
\text { Navarro }\end{array}$ & Ecléctico & 1927 \\
\hline 149 & $\begin{array}{l}\text { S/C de } \\
\text { Tenerife }\end{array}$ & Ud. Instal 92/37 & Carretera del Quisisana & Ecléctico & 1927 \\
\hline 150 & $\begin{array}{l}\text { S/C de } \\
\text { Tenerife }\end{array}$ & Ud. Instal 93/54 & $\begin{array}{l}\text { Avenida de las } \\
\text { Asuncionistas }\end{array}$ & Ecléctico & 1927 \\
\hline 151 & $\begin{array}{l}\text { S/C de } \\
\text { Tenerife }\end{array}$ & Ud. Instal 93/56 & $\begin{array}{l}\text { C/ de Salamanca } \\
\text { esquina a c/ de la } \\
\text { Igualdad }\end{array}$ & Ecléctico & 1927 \\
\hline 152 & $\begin{array}{l}\text { S/C de } \\
\text { Tenerife }\end{array}$ & Ud. Instal 93/73 & C/ de la Rosa n. ${ }^{\circ} 45$ & Ecléctico & 1927 \\
\hline 153 & $\begin{array}{l}\text { S/C de } \\
\text { Tenerife }\end{array}$ & Ud. Instal 93/82 & C/ de Noria Alta & Ecléctico & 1927 \\
\hline 154 & $\begin{array}{l}\text { S/C de } \\
\text { Tenerife }\end{array}$ & $\begin{array}{l}\text { Ud. Instal } \\
94 / 108\end{array}$ & $\begin{array}{c}\text { C/ Lucas Fernández } \\
\text { Navarro }\end{array}$ & Ecléctico & 1927 \\
\hline 155 & $\begin{array}{l}\text { S/C de } \\
\text { Tenerife }\end{array}$ & $\begin{array}{l}\text { Ud. Instal } \\
94 / 128\end{array}$ & $\begin{array}{l}\text { C/ Alfonso XIII n. }{ }^{\circ} \\
52 \text { esquina a c/ Juan } \\
\text { Padrón }\end{array}$ & Ecléctico & 1927 \\
\hline 156 & $\begin{array}{l}\text { S/C de } \\
\text { Tenerife }\end{array}$ & $\begin{array}{l}\text { Ud. Instal } \\
95 / 138\end{array}$ & $\begin{array}{c}\text { C/ n. } 3 \text { y } 10 \text { del barrio } \\
\text { de Salamanca }\end{array}$ & Ecléctico & 1927 \\
\hline 157 & La Laguna & $\begin{array}{l}\text { Ud. Instal } \\
609 / 63\end{array}$ & C/ del Juego & Ecléctico & 1929 \\
\hline 158 & La Laguna & Ud. Instal 610/7 & C/ Alfonso XIII n. ${ }^{\circ} 28$ & Ecléctico & 1930 \\
\hline 159 & La Laguna & $\begin{array}{c}\text { Ud. Instal } \\
610 / 22\end{array}$ & $\begin{array}{l}\text { C/ de Sol y Ortega } \\
\text { n. }{ }^{\circ} 24\end{array}$ & Ecléctico & 1930 \\
\hline 160 & Garachico & Ud. Instal 40/16 & $\begin{array}{l}\text { C/ de Pérez Zamora } \\
\text { esquina a prolongación } \\
\text { Callejón de la } \\
\text { Carnicería }\end{array}$ & Ecléctico & 1930 \\
\hline
\end{tabular}

La cantidad de edificios de Pintor supera con creces a los demás, pero esto también es debido a la gran capacidad de trabajo y dedicación que poseía Pintor como indica DARIAS (1985: 179-180). Para su estudio los agruparemos por fechas. 
En un primer grupo reunimos un total de 10 edificios entre 1909 y 1913. Comenzamos por el número 64, primer edificio localizado con remate de cubierta en el que Pintor opta por una variante sencilla del clásico diseño en esfera de la figura 2 izquierda sobre base en la que se disponen dos sencillos roleos. El remate se sitúa sobre el antepecho de cubierta, en línea con la vertical de las pilastras del nivel inferior. Darias nos indica que los antepechos de la azotea nos van a definir el estilo de Pintor (DARIAS, 1985: 193), aunque realmente donde nos vamos a fijar será en lo que ocurre sobre él. De los siguientes edificios de este primer tramo, destacamos en primer lugar que se encuentra un edificio claramente modernista, el n. ${ }^{\circ} 68$, que cuenta con remate de cubierta utilizando una variante del clásico diseño sencillo en esfera que mostramos en la figura 2 izquierda. Además, observamos una predilección de Pintor por los herrajes de antepecho en la mayoría de los balcones, por lo que no cuenta con nuestro remate en ellos, ubicado exclusivamente en el antepecho de la cubierta; en algunos de estos herrajes se observa su faceta modernista, como ocurre con el edificio n. ${ }^{\circ}$ 64. Volviendo a los remates, es frecuente en Pintor el diseño sencillo en esfera utilizado en cuatro ocasiones, con algunas variantes vegetales. El diseño en copa cerrada se encuentra en dos casos, con gran enriquecimiento ornamental y también varía a otras formas singulares en urna, destacando el atractivo diseño en huevo sobre roleos del edificio $\mathrm{n}^{\circ}{ }^{\circ} 65$. No se tiende a la esbeltez de los detalles, Darias afirma que en Pintor priman los remates sobre los pináculos, estos últimos más tardíos (DARIAS, 1985: 194). En general se observa una gran finura de trazos en todos los edificios.

Con respecto a la relación con la fachada destacamos el edificio modernista n. ${ }^{\circ} 68$, en el que cabría esperar un remate acorde con la decoración singular del resto, pero esto no ocurre, sino que en este ejemplo, Pintor vuelve a demostrar su apego por los clásicos diseños en esfera.

El siguiente grupo de edificios lo forman un total de doce, desde el año 1914 hasta 1921. En ellos se sigue manteniendo el antepecho de los balcones con herrajes, por lo que el remate de cubierta solo se ubica en la azotea, con la salvedad de que en el edificio $n$. $^{\circ} 79$ además lo incluye en los laterales del dintel de los huecos, como podemos apreciar en la figura 8 derecha. En este mismo edificio y junto con el n. ${ }^{\circ} 83$, se aumenta la esbeltez de los remates acercándose más a un pináculo, imagen que mostramos en la figura 8 izquierda, pero también en el n. 79 se dispone otro remate de esbeltez normal, con forma de seta lobulada sobre pedestal. La calidad de los remates de este periodo decae un poco. Pintor prescinde del diseño sencillo en esfera del grupo anterior y opta por formas de florales entre hojas, copas con tapa o composiciones geométricas como cilindros combinadas con roleos, y si opta por el diseño en esfera, lo desdibuja con aporte de elementos vegetales.

Como se ha descrito, Pintor puede combinar varios tipos de remates dentro de un mismo edificio, eligiendo estratégicamente el diseño con la ubicación: en la fachada de la figura 8 derecha se puede identificar un cuerpo central flanqueado por dos torreones, que refuerzan su altitud mediante estos remates agudos. Sin embargo, en la cubierta más baja situada entre ellos, reduce el remate para acentuar el contraste y realzar la altitud de las torres. 

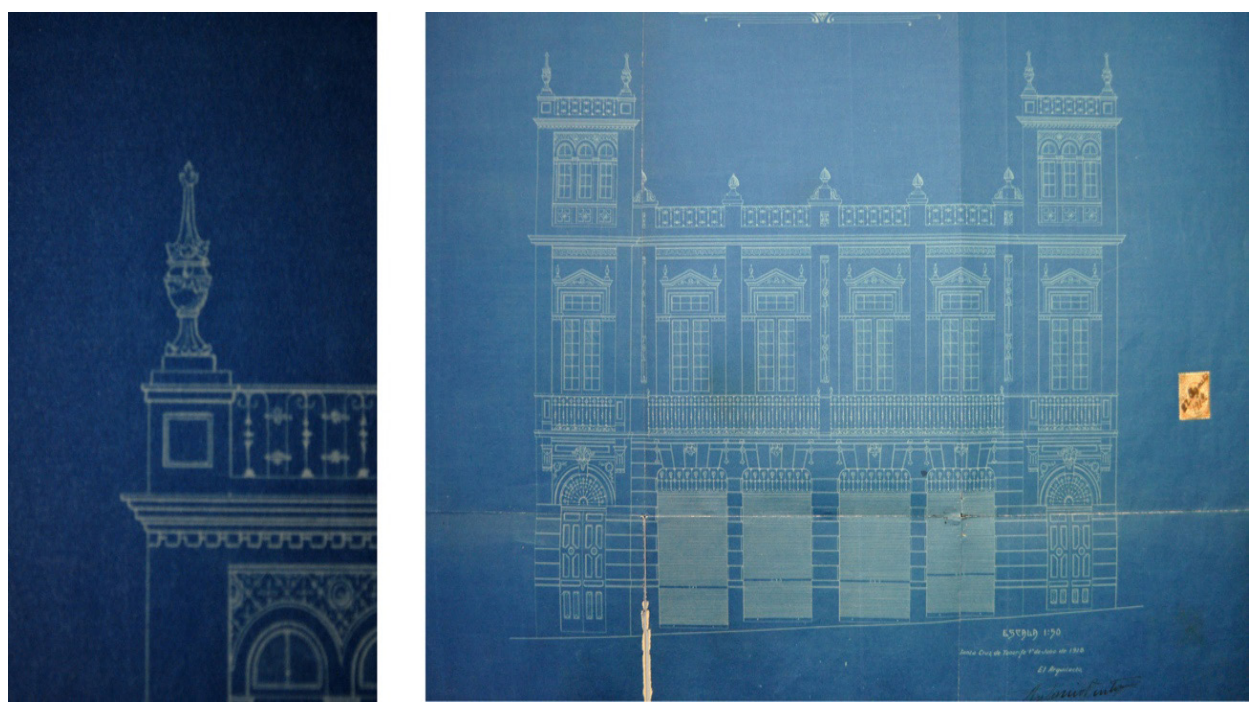

Figura 8. Remate de cubierta. Ornato público. Ud. Instal 17-47. Archivo Municipal S/C TFE. Arquitecto Antonio Pintor (izquierda). Fachada. Ornato público Unidad de instalación 17-47. Archivo Mpal. S/C de Tfe. Arquitecto Antonio Pintor (derecha). Fotos: José Antonio Sabina González.

El tercer grupo de edificios de Pintor con remates de cubierta se concentra en los años 1922 y 1923 con 13 inmuebles. En ellos, el autor no utiliza tanto el herraje de balcón como antepecho, sustituyéndolo por obra de fábrica o balaustres por lo que ya se pueden ver algunos ejemplos de nuestro remate sobre él, concretamente en los edificios n. ${ }^{\circ} 88,92,93,95$ y 98, y si dispone del herraje, en algunos a casos lo ubica entre pilaretes sobre los que ubica nuestro ornato como ocurre con el edificio n. ${ }^{\circ}$ 98. La calidad de los remates de cubierta se incrementa notablemente con respecto al grupo anterior, con una finura de trazos minuciosa, como presentan por ejemplo los edificios n. ${ }^{\circ} 86,87,92,96,97$. Se observa que Pintor incrementa la esbeltez de algunos de ellos en más casos para acercarse a los pináculos, como ocurre con el edificio n. ${ }^{\circ}$ Vegueta 90 y en los edificios n. ${ }^{\circ} 92$ y 93 de 1923 ya pueden considerarse plenamente como pináculos. Pintor vuelve a dejar de lado el diseño sencillo en esfera de sus inicios, pero sí lo utiliza como base para componer esta esfera pero sobre capullo de acanto, como ocurría con Pisaca, concretamente en los edificios n. ${ }^{\circ} 97$ y 98, con una gran sutileza en el acanto, mostrado en la figura 7 derecha. Se observa que en algunos casos tiende a achatar el remate, dispuesto en los edificios n. ${ }^{\circ} 88,89$ y 95 , y su diseño de copa con tapa tiene menos presencia salvo en el n. ${ }^{\circ} 91$.

A partir de aquí se incrementa la cantidad de edificios de Pintor con remates de cubierta. Solamente en el año 1924 nos encontramos con 15 casos que forman nuestro cuarto grupo. En ellos podemos observar una singularidad entre los edificios n. ${ }^{\circ} 99$ y 101, en los que Pintor introduce un remate que podría parecer un jarrón porque no presenta tapa, pero su perímetro superior lobulado hace 
recordar más bien la forma de una torre de ajedrez. En algunos casos opta por el diseño simple en esfera, como ocurre en los edificios n.$^{\circ} 102$ y 111, o el diseño en seta algunas veces con atractivas franjas, como ocurre con los edificios n. ${ }^{\circ}$ 103,106 y 108. Además, incluye su habitual esfera sobre acanto, en los edificios n. ${ }^{\circ}$ 104 y 105, creando una singularidad al respecto en el edificio n. ${ }^{\circ} 104$, y es que lo combina con dos bases distintas, una más esbelta que otra para ayudar a crear una diferencia de altitud en la cubierta que realza uno de sus lados. Lo mismo acurre con el edificio n. ${ }^{\circ} 112$, otra combinación similar de diseños, pero en este caso con la forma de copa con tapa, o simplemente lo incluye sin combinar, como ocurre en los edificios n. ${ }^{\circ}$ 100, 109 y 113 con esta última forma. Pintor a veces busca referencias que le inspiren, como sucede con el edificio $\mathrm{n}^{\circ} 107$ en el que versiona una flor de lis, y aumenta en algunos casos la esbeltez del remate para emular a pináculos en los edificios n. ${ }^{\circ} 110$ y 112. En cuanto a la ubicación del remate, en este año deja de lado los antepechos de los balcones, reservando el de la cubierta para ubicar nuestro ornato.

Al año siguiente, en 1925, Pintor vuelve a utilizar el remate de cubierta en otro gran número de edificios, otros 15 . Lo más característico es que destaca el diseño de copa con tapa, utilizado en la mayoría de los inmuebles, como ocurre con el n. ${ }^{\circ}$ $115,116,118,119,121,123,126,127$ y 128. Las demás formas incluidas en menor grado son: en seta, en esfera sobre acanto, con formas ovales con malla sobre acanto a modo de piña o esferas encintadas. Solamente en un caso encontramos el diseño de peón de ajedrez combinado con la esfera sobre acanto, en el edificio n. ${ }^{\circ} 117$, en el que el arquitecto juega con la escala del remate según se ubique sobre la pilastra o entre ellas, pero siempre en la cubierta. En todos los casos, el lugar elegido sigue siendo el antepecho de la misma, con solo dos ejemplos en el balcón, en los edificios n. ${ }^{\circ} 119$ y 120 , con un diseño con forma de farol y otro en los laterales del dintel, en el edificio n. ${ }^{\circ} 121$. La inventiva de Pintor también le lleva a componer un curioso diseño de remate con roleos de grandes dimensiones en el edifico $\mathrm{n}^{\circ} 122$, que alterna con otro más pequeño de esfera sobre acanto. A veces se reduce la calidad de algunos detalles del remate, como si primara cierta prisa, circunstancia que ocurre en los edificios n. ${ }^{\circ} 126$ y 128, no apreciándose tendencias al pináculo para este año.

En 1926 se produce la mayor cantidad de edificios de Pintor con remates de cubierta, concretamente con 17. En este año se observa una tendencia del arquitecto en combinar dos diseños, la copa con tapa y la esfera sobre base, circunstancia que ocurre en los edificios n. ${ }^{\circ} 129$ y 132, con la esfera formando el típico peón de ajedrez en este último. Y otra tendencia: dispone un remate chato cuya parte superior adopta la forma de carpa de circo, como ocurre con los edificios n. ${ }^{\circ} 142$ y 145, con una versión de esbeltez normal en los inmuebles n. ${ }^{\circ}$ 130 y 140. Sigue su tendencia de evitar los remates en los balcones prefiriendo el antepecho de la cubierta, salvo en el edificio n. ${ }^{\circ} 135$ que ocurre todo lo contrario, donde los coloca únicamente en el balcón con un diseño de campana y en los laterales del dintel. Continúa predominando el diseño de copa con tapa, utilizado en los edificios n. ${ }^{\circ}$ 130, 131, 132, 133, 136, 138, 140, 143 y 144 y en el 129 con dos esbelteces distintas. Otros diseños menos utilizados son la esfera sobre roleos, formas ovales en malla sobre capullo, el huevo sobre pedestal y figuras similares a la torre de ajedrez del año anterior pero más anchas. En el edificio n. ${ }^{\circ} 133$ se produce una singularidad, y es que encontramos nuestro remate sobre la clave del arco de entrada, también situado en los laterales del mismo, y por su puesto 
en la cubierta, con una combinación de molduras que unen varias esferas lobuladas para aportar esbeltez. En algunos edificios la sencillez del remate sigue insinuando cierta prontitud en la elaboración del proyecto, como si en este año en general se deja un poco de lado la elaboración ornamental del remate, salvo excepciones, quizás debido a que la mayoría de los edificios son de una planta, sin gran majestuosidad o importancia especial.

Pasamos a 1927 y lo que se observa es que se reduce drásticamente el número de edificios con remates de cubierta de Pintor, quedando un total de 11. En ellos destacamos una evolución del diseño en torre de ajedrez que a veces utilizaba, concretamente puede verse en el edificio n. ${ }^{\circ} 146$ : le aporta más grueso y la parte superior ya no aparece un almenado sino más bien una corona. En los laterales del dintel de la planta segunda opta por el sencillo diseño en esfera a corta escala. Sigue fiel a su diseño de copa con tapa que utiliza en los edificios n. ${ }^{\circ} 147,148,152$ y 156 con una variante, y es que en el edificio n. ${ }^{\circ} 149$ lo dispone sobre acanto. Otros diseños que utiliza son su esfera sobre acanto, capullos sobre roleos y formas ovoides sobre campana. Se observa en algunos inmuebles la tendencia al pináculo de los remates, en los que el estilo que muestra nuestro arquitecto es componer una torre moldurada que culmina en esfera o bien en media esfera, carpa de circo o copa con tapa esbelta. Pintor sigue prefiriendo la cubierta, solamente se encuentra un caso de remate en el balcón y es el edificio n. ${ }^{\circ} 156$ con una forma floral indeterminada. En general la definición y minuciosidad de los remates se ha incrementado considerablemente respecto al año anterior.

A partir de aquí, los remates de cubierta casi no están presentes. No se han detectado casos en 1928, y posteriormente pocos y no en Santa Cruz de Tenerife. Es decir, un caso en 1929 en La Laguna, el edificio n. ${ }^{\circ} 157$, con su diseño de peón de ajedrez y en 1930 tres casos: dos en La Laguna, en el edificio n. ${ }^{\circ} 158$ con un diseño de copa con tapa y en el edificio n. ${ }^{\circ} 159$ la forma oval sobre capullo del estilo de la figura 4 derecha. Por último en el edificio n. ${ }^{\circ} 160$ de Garachico, compone una forma floral sobre acanto sobre el antepecho de cubierta, lugar que ocupan todos estos nombrados, pero además en este último ubica otros remates más pequeños en los laterales del dintel de la puerta de entrada, con su clásica forma de peón de ajedrez, y en las puertas de balcón una variante que recuerda esta torre de ajedrez.

\section{CONCLUSIONES}

Todos los ornatos aportan su particular contribución al embellecimiento de la fachada, pero la utilización o no del remate de cubierta junto con su forma y ubicación permite diferenciar mucho el resultado final. Hemos visto que los arquitectos tienen sus preferencias de utilización, pero en líneas generales según es el edificio, tanto en importancia como en número de plantas debe ser el remate: en el caso de edificios de una planta el remate debe poseer su medida justa, comedido para aportar elegancia. A medida que se aumenta el número de plantas el remate puede ganar en esbeltez para conseguir sensación de verticalidad.

En cuanto a los lenguajes, a pesar del ejemplo mostrado en un edificio modernista, realmente es en edificios eclécticos donde predomina, aunque algunos incluyan algún elemento art-nouveau en un herraje o en un tragaluz

La fecha de los inmuebles determina una cronología de uso: El primer ejemplo localizado pertenece a Manuel de Cámara en 1896; a continuación 
Antonio Pintor con un ejemplo de 1909; Mariano Estanga le sigue con un ejemplo de 1910; posteriormente Antonio Martín Nuñez (1915), sigue Domingo Pisaca (1922), continúa Otilio Arroyo (1924), y por último Javier Felip Solá y Pelayo López y Martín Romero con un ejemplo de 1926 cada uno.

La utilización del remate de cubierta por parte de Antonio Pintor es muy alta, con un total de 97 edificios, a pesar de también influir su gran capacidad de trabajo que indicaba Darias para realizar proyectos; le sigue Domingo Pisaca, con 44 edificios y a partir de aquí es más moderado el uso, de los que destacamos Javier Felip Solá con ocho y Mariano Estanga con cuatro.

Sus características particulares sobre nuestro ornato son las siguientes:

Sobre Manuel de Cámara podemos decir que prefiere utilizar el remate cuando se trata de un edificio de gran importante decorativa y de varias plantas, con la preferencia de ubicación sobre el antepecho de cubierta. Con los pocos ejemplos localizados no parece que suela contar con él. Darias comenta como Cámara no suele decorar los coronamientos, limitándose generalmente solo a los antepechos (Darias, 1985: 147). No obstante en los casos mostrados le aporta todos los detalles que permite la mano alzada, no repite diseño, los varía atractivamente y según nuestros datos, es el arquitecto que comenzó a utilizarlo. Si lo incorpora en las plantas inferiores le aumenta su esbeltez para compensar la sensación de altura, aparentando más un pináculo.

Antonio Martín Núñez tampoco utiliza mucho este recurso a las vista de los edificios localizados, pero no duda en variar los diseños incluso dentro de un mismo plano cuando se decide por él, y lo inserta a partir de las dos plantas. No los ubica sobre el antepecho de los balcones, ni siquiera modificando su esbeltez, sino solamente en la cubierta, define mucho los detalles pero sin precisar demasiado.

Otilio Arroyo marca un estilo propio en sus remates de cubierta. Su diseño en pequeñas copas cerradas precedidas por multitud de molduras en cimacio, bocel etc. tiene cierto grado de esbeltez, algo próximos a un pináculo, y además los presenta agrupados. Utiliza tanto el antepecho de cubierta como la cornisa del dintel para ubicarlo, pero no se puede afirmar que el elemento estudiado sea habitual en él.

En los dos imponentes edificios de Pelayo López y Martín Romero se revela su predilección por los grandes ventanales y puertas que en todas las plantas son las protagonistas. Su decoración no es demasiado abundante, comparado con un Pisaca o un Pintor, pero es muy minucioso precisando cada detalle. Darias indica como Pelayo, comenzó a declinar en su opulencia decorativa (Darias, 1985: 348) en su segunda etapa que corresponde con la fecha (1926) de los ejemplos que mostramos. Este arquitecto no suele utilizar mucho nuestro remate, por los pocos casos identificados, pero no duda en incluirlo cuando se trata de edificios con un número importante de plantas para la época (4) y procura no repetir el diseño.

Sobre Mariano Estanga podemos hablar de evolución. Inicialmente alternaba pináculos con remates, comenzando a utilizar el sencillo diseño en esfera de la figura 2 izquierda como base aportándole algunas modificaciones, práctica que mantuvo en sus siguientes edificios, pero finalmente terminó con diseños más elaborados y variados. No son tantos los edificios localizados con nuestro elemento decorativo, Darias indica que sus remates son raros y que cuando recurre a ellos utiliza su jarrón de boca ancha (Darias, 1985: 319), pero hemos visto que tampoco podemos decir que no cuente con ellos, sobre todo por la gran variedad de remates que incluye al final en un mismo edificio. Si los utiliza, prefiere el 
antepecho de cubierta para ubicarlos.

Javier Felip Solá posee una predilección clara por el diseño sencillo en esfera de la figura 2 izquierda para el remate de cubierta, aunque a veces inserta la copa cerrada. En sus planos intenta insinuar las formas de los ornatos, más que definirlas, sobre todos en sus primeros ejemplos, marcando solo el perfil de los mismos aunque más tarde opta por trazar las líneas internas de ellos; de todas maneras debe indicarse que sus edificios localizados con nuestro remate tienen fechas muy próximas, entre 1926 y 1931. Prefiere la ubicación de los mismos sobre el antepecho de cubierta, y a veces sobre el dintel de las puertas principales de entrada si cuenta con pórtico clásico. Esto último nos revela un gusto por los detalles de la arquitectura ancestral por parte de Solá. Utiliza nuestro remate de forma moderada.

Domingo Pisaca utiliza el remate de cubierta de forma habitual, con diseños muy definidos y trazos minuciosos. No es partidario de repetir diseños, le gusta innovar, siendo capaz de tomar la sencilla forma en esfera de la figura 2 izquierda y aportarle tales complementos en su justa medida que lo convierte en un atractivo elemento ornamental creando un diseño propio, preferentemente ubicado en un lugar importante como la cubierta. También a veces usa su versión sencilla en esfera en los balcones y dinteles de los huecos. La variedad de ubicaciones vista hasta el momento, se amplía: antepecho de cubierta y balcón, dinteles, laterales del alfeizar etc. Comienza a utilizar nuestro remate tímidamente en 1922 con un 4,6 \% para irlo incrementando en 1923 con un 9,3 \% hasta llegar en 1924 y 1925 con un 27,9 y 25, 6 \% respectivamente, los años que más lo utiliza, aunque en 1925 la calidad de los ornatos es mayor; luego se ha ido reduciendo en 1926 con un $18,6 \%$ y finalmente en 1927 con un $14 \%$. Pisaca decora abundantemente y con mucha calidad la fachada, pero en líneas generales suele decorarla acorde a la importancia y con el número de plantas del edificio: con una planta es más moderada, con dos podemos considerarla de tipo medio y a partir de aquí suele desatarse toda la capacidad creativa de Pisaca.

Antonio Pintor también es minucioso y detallista, con una finura de trazos notable y elegante, reflejando su influencia art-nouveau en algunos de sus herrajes de balcón. Al utilizar el metal en ellos, más que Pisaca, no les incorpora remates, destinándolos mayormente al antepecho de la cubierta en sus inicios. Luego optará por alternar antepechos de fábrica en el balcón, a partir de 1922, cuando ya comenzará a ubicar sobre ellos nuestro ornato, pero posteriormente se valora que no es su lugar predilecto.

En sus comienzos, Pintor opta por el sencillo diseño en esfera que posteriormente sustituye por otras formas con detalles orgánicos y unidades más esbeltas que recuerdan a un pináculo, pero se volverá a recuperar más delante, sin dejar de utilizar las nuevas variantes incorporadas. Posteriormente, las inspiraciones en formas establecidas también forman parte del repertorio de Pintor, como la flor de lis o la torre de ajedrez, no dudando tampoco en variar la esbeltez de un mismo diseño dentro de un mismo edificio. Más tarde, su copa con tapa gana protagonismo, combinándola con el diseño en esfera y finalmente los pináculos vuelven a establecerse, culminados con formas esféricas. En general se observa que, a menor cantidad de edificios, la calidad de elaboración y detallismo de los mismos aumenta considerablemente. A partir de aquí se reducen los casos, hasta 1930.

Evidenciamos que Pintor comenzó a utilizar nuestro elemento decorativo 
de forma progresiva, pero a diferencia de Pisaca, comenzó con ciertos titubeos de utilización entre 1909 y 1921, realmente iniciando su uso en 1922 con más frecuencia, para finalmente en 1924, 1925, 1926 y 1927 utilizarlo abundantemente. Como se ha apuntado, posteriormente redujo su uso hasta 1930, año en el que se detectó su último caso.

En cuanto a la presencia geográfica, debe indicarse que depende mayormente de la cantidad de edificios del núcleo poblacional y su importancia, porque será más probable la presencia del remate, y del puesto del arquitecto que utiliza nuestro ornato. Por estos motivos, resulta evidente que Santa Cruz de Tenerife concentre la mayor parte de los casos, especialmente porque el arquitecto más prolífico, Antonio Pintor, fue su arquitecto municipal, pero también Pisaca concentra su trabajo en esta su ciudad natal, el segundo autor con más edificios con el remate. Siguiendo con el número de casos el siguiente puesto lo ocupa La Laguna, en la que también Pintor, Pisaca, Solá y Estanga también tienen algunos edificios. Seguidamente la siguiente ciudad es el Puerto de la Cruz, cuyos protagonistas son Antonio Martín, aparejador municipal de esta ciudad y Solá, su arquitecto municipal en los inicios de su carrera. Le sigue La Orotava en las que destaca Estanga, posiblemente por estar muy relacionado por motivos personales con este municipio y finalmente en Garachico encontramos un caso de Pintor.

En este recorrido que hemos realizado a través de las tendencias ornamentales de los técnicos que han hecho posible que contemos con un patrimonio arquitectónico importante, debemos indicar que también contribuye al entendimiento de nuestra historia el estudio detallado de cada elemento que nos indica sus preferencias.

\section{REFERENCIAS}

«Arabescos: Paneles decorativos del renacimiento» (1996): Enciclopedia de la ornamentación, Gustavo Gili, México.

EsPasA CALPE, S. A. (1991): Enciclopedia universal ilustrada europeo-americana, EspasaCalpe, Madrid.

Darias PRíncIPE, A. (1991): Arquitectura en Canarias: 1777-1931, Centro de la Cultura Popular Canaria, La Laguna.

DARIAs PRíNCIPE, A. (1985): Arquitectura y arquitectos en las Canarias occidentales, 1874 1931, Editorial confederación de Cajas de Ahorros, Santa Cruz de Tenerife.

DARIAS PRÍNCIPE, A. (2004): Ciudad, arquitectura y memoria histórica 1500-1981, Ayuntamiento de Santa Cruz de Tenerife, Santa Cruz de Tenerife.

FERnÁNDEZ FERnÁNDEZ, X. (1995): Arquitectura del Eclecticismo en Galicia (1875-1914), Universidade da Coruña, A Coruña.

Franchez ApezetXeA, J.L. (2009): El arte de construir: Del Románico al Eclecticismo en la arquitectura, EUNSA, Pamplona.

Gago VaQuero, J.L. (ed.) (1989): La Ciudad de Las Palmas de Gran Canaria y la cultura modernista, Cabildo Insular de Gran Canaria, Centro Insular de Cultura, Las Palmas de Gran Canaria.

Gallardo Peña, M. (1984): El Clasicismo Romántico en Santa Cruz de Tenerife, Tesis doctoral inédita, Universidad de La Laguna, Departamento de Historia del Arte, La Laguna. 
García de Paredes Pérez, E.A. (1996): «Pervivencia del lenguaje clásico en el eclecticismo canario», Boletín de Arte, 17: 315-326.

Martín Rodríguez, F.G. (1978): Arquitectura doméstica canaria, 2a ed., Aula de Cultura de Tenerife, Santa Cruz de Tenerife.

Otero Alia, F.J. (1991): «El debate en torno al ornamento arquitectónico en la revista arquitectura y construcción: 1897-1922», Espacio, Tiempo y Forma, Serie VII, Historia del Arte, 4: 425-458

Plaza Escudero, L. de la; Martínez Murillo, J.M. (2012): «Diccionario visual de términos arquitectónicos, $2^{\mathrm{a}}$ ed., Cátedra, Madrid.

Poblador Muga, M.P. (2004): «El modernismo en la arquitectura y en las artes», Argensola: Revista de Ciencias Sociales del Instituto de Estudios Altoaragoneses, 114: 13-62.

Sabina González, J.A. (2019): El ornato arquitectónico en Tenerife (1880-1935). Catalogación y análisis morfológico de sus lenguajes, Tesis doctoral inédita, Universidad de La Laguna, La Laguna.

SANCHO Corbacho, A. (1947): Dibujos arquitectónicos del siglo XVII: Una colección inédita de 1663, Consejo Superior de Investigaciones Científicas, Instituto «Diego Velázquez», Sección de Sevilla, Sevilla.

Zalba GonZÁlez, E. (2008): «Vanguardia y arquitectura en la década de 1930: Proyectos inéditos de José Blasco Robles para el Puerto de la Cruz», Revista de Historia Canaria, 190: 135-168.

Zalba GonZÁlez, E. (2009): «Tradición y modernidad en el Puerto de la Cruz: Dos ejemplos en la arquitectura de los años 30», Revista de Historia Canaria, 191: 229-256. 
